\title{
Metallonics
}
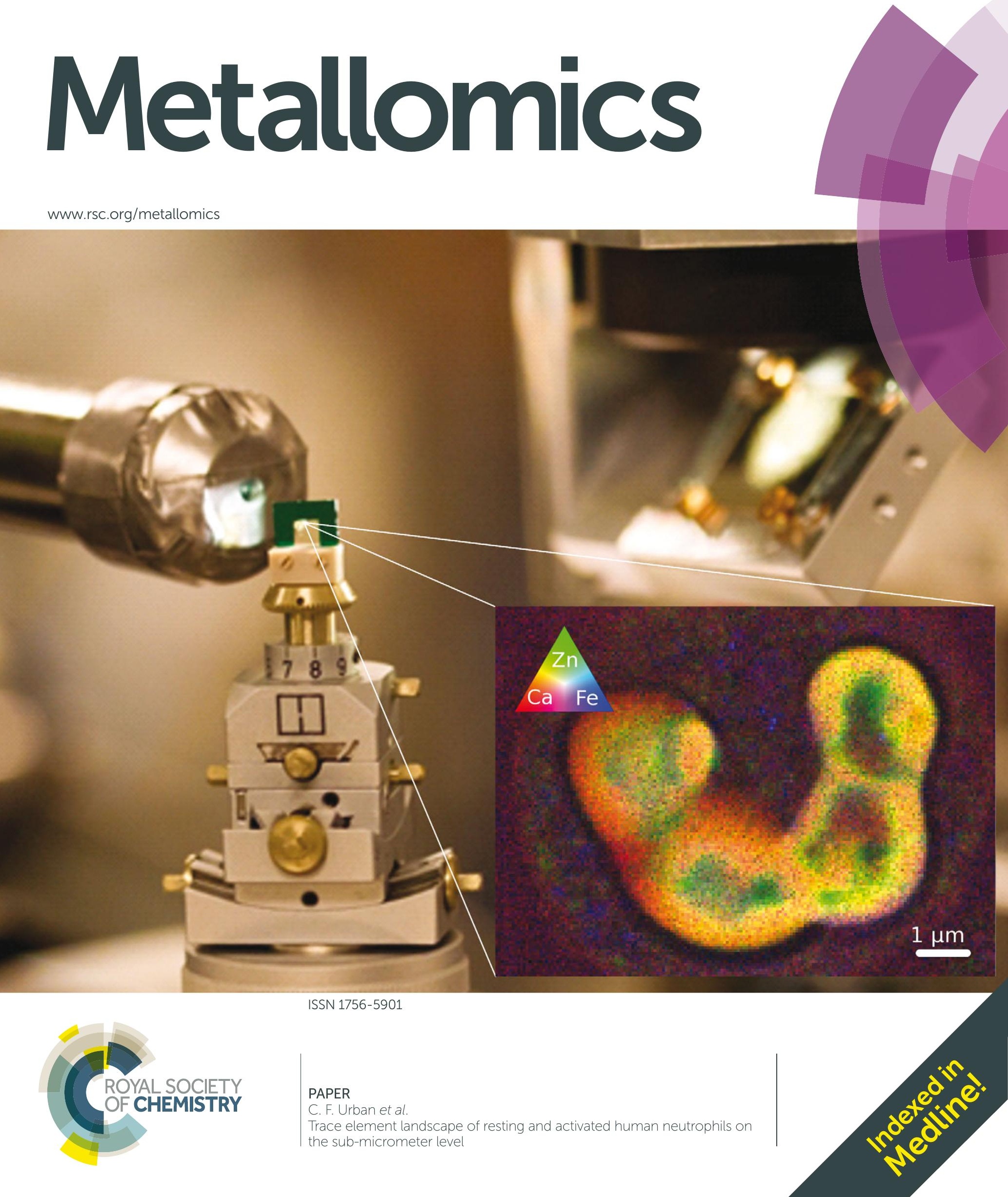


\title{
Metallomics
}

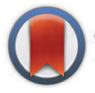

CrossMark <click for updates

Cite this: Metallomics, 2015 7, 996

Received 22nd December 2014, Accepted 20th March 2015

DOI: $10.1039 / \mathrm{c} 4 \mathrm{mt} 00346 \mathrm{~b}$

www.rsc.org/metallomics

\section{Trace element landscape of resting and activated human neutrophils on the sub-micrometer level $\dagger$}

\author{
M. J. Niemiec, ${ }^{a}$ B. De Samber, ${ }^{\text {b }}$ J. Garrevoet, ${ }^{b}$ E. Vergucht, ${ }^{b}$ B. Vekemans, ${ }^{b}$ \\ R. De Rycke, ${ }^{c}$ E. Björn, ${ }^{d}$ L. Sandblad, ${ }^{e}$ G. Wellenreuther, ${ }^{f}$ G. Falkenberg, ${ }^{f}$ \\ P. Cloetens, ${ }^{9}$ L. Vincze ${ }^{b}$ and C. F. Urban ${ }^{{ }^{a}}$
}

\begin{abstract}
Every infection is a battle for trace elements. Neutrophils migrate first to the infection site and accumulate quickly to high numbers. They fight pathogens by phagocytosis and intracellular toxication. Additionally, neutrophils form neutrophil extracellular traps (NETs) to inhibit extracellular microbes. Yet, neutrophil trace element characteristics are largely unexplored. We investigated unstimulated and phorbol myristate acetate-stimulated neutrophils using synchrotron radiation X-ray fluorescence (SR-XRF) on the sub-micron spatial resolution level. PMA activates pinocytosis, cytoskeletal rearrangements and the release of NETs, all mechanisms deployed by neutrophils to combat infection. By analyzing $\mathrm{Zn}, \mathrm{Fe}, \mathrm{Cu}, \mathrm{Mn}, \mathrm{P}, \mathrm{S}$, and $\mathrm{Ca}$, not only the nucleus but also vesicular granules were identifiable in the elemental maps. Inductively Coupled Plasma Mass Spectrometry (ICP-MS) revealed a neutrophil-specific composition of Zn, $\mathrm{Fe}, \mathrm{Cu}$, and $\mathrm{Mn}$ in comparison with $\mathrm{J774}$ and HeLa cells, indicating a neutrophil-specific metallome complying with their designated functions. When investigating PMA-activated neutrophils, the SR-XRF analysis depicted typical subcellular morphological changes: the transformation of nucleus and granules and the emergence of void vacuoles. Mature NETs were evenly composed of Fe, $\mathrm{P}, \mathrm{S}$, and Ca with occasional hot spots containing Zn, Fe, and Ca. An ICP-MS-based quantification of NET supernatants revealed a NETosis-induced decrease of soluble $\mathrm{Zn}$, whereas $\mathrm{Fe}, \mathrm{Cu}$, and $\mathrm{Mn}$ concentrations were only slightly affected. In summary, we present a combination of SR-XRF and ICP-MS as a powerful tool to analyze trace elements in human neutrophils. The approach will be applicable and valuable to numerous aspects of nutritional immunity.
\end{abstract}

\section{Introduction}

Metal ions play an important role in many biological processes. They catalyze reactions, stabilize structures, and act during gene regulation or cell signaling. ${ }^{1-5}$ Their usage is conserved in prokaryotes and eukaryotes. ${ }^{6}$ During infections, when the host encounters microbial invaders, metal ions are essential for survival of both parties. The host therefore restricts the availability of metal ions in order to avoid microbial growth - a strategy named "nutritional immunity" and described in animals and plants. ${ }^{7}$ In response,

\footnotetext{
${ }^{a}$ Department of Clinical Microbiology/MIMS, Umeå University, Sweden. E-mail: constantin.urban@umu.se

${ }^{b}$ Department of Analytical Chemistry, Ghent University, Belgium

${ }^{c}$ IRC-PSB Transmission Electron Microscopy-Core Facility, Ghent University, Belgium

${ }^{d}$ Department of Chemistry, Umeå University, Sweden

${ }^{e}$ Department of Molecular Biology, Umeå University, Sweden

${ }^{f}$ Petra III, DESY, Hamburg, Germany

${ }^{g}$ European Synchrotron Radiation Facility, Grenoble, France

$\dagger$ Electronic supplementary information (ESI) available. See DOI: 10.1039/ $\mathrm{c} 4 \mathrm{mt} 00346 \mathrm{~b}$
}

many pathogens have evolved sophisticated tools to chelate metal ions from the host and these tools are targeted by the host in return. This interplay illustrates co-evolution of host and pathogen and is best exemplified by the well-studied fight for $\mathrm{Fe}^{8}$ In the host, Fe is mainly kept intracellular - free Fe is essentially unavailable in blood or other extracellular liquids. It is bound to transferrin in plasma and lactoferrin in external secretions. Microbial pathogens have two mechanisms to cope with these limitations. In case of direct contact between the host Fe source and the pathogen, host Fe-retaining proteins are modified to release their Fe load into the extracellular environment for uptake. Secondly, many bacteria and fungi secrete siderophores, small molecules with exceptionally high Fe affinity that free Fe from host proteins followed by resorption into the pathogenic cell. As a response, mammals produce lipocalin-2, to intercept siderophores. This can in turn be counteracted by many pathogens which disguise their siderophores by glycosylation. ${ }^{8}$

Fe is not the only transition metal important in nutritional immunity. $\mathrm{Zn}, \mathrm{Mn}$ and $\mathrm{Cu}$ are also shown to be critical. ${ }^{9,10}$ Especially $\mathrm{Zn}$ has been demonstrated to be crucial during fungal pathogenicity. ${ }^{11}$ This can be explained by its unique biochemical 
features which are reflected in the utilization in different organisms. $\mathrm{Zn}$ is a strong Lewis-acid, water-soluble at the oxidated state $+\mathrm{II}$ and also redox-stable under standard physiological conditions. ${ }^{12}$ About $7 \%$ of the entire proteome of archaea, bacteria and eukaryotes are predicted to be $\mathrm{Zn}$ proteins. ${ }^{13}$ In addition to the enzymatic function in peptidases, amidases and esterases - conserved to similar extent in all kingdoms - Zn functions also in Zn-finger proteins to mediate binding to DNA and RNA. Whereas bacteria and archaea have less than $0.5 \%$ of $\mathrm{Zn}$-finger proteins, eukaryotes have about $3 \%$ - so almost half of the entity of their Zn proteome. ${ }^{13}$ In agreement with this, fungi are especially susceptible to $\mathrm{Zn}$ depletion. Shortage of $\mathrm{Zn}$ has been shown to cause intracellular oxidative stress in yeast. ${ }^{14}$ Also, the fungal pathogen Candida albicans was found to be completely growth arrested, if the surrounding concentration of $\mathrm{Zn}$ drops below $1 \mu \mathrm{M} .^{15}$

Neutrophils play a crucial role in the immune defense against fungal and bacterial pathogens. Once a pathogen passes the mechanical barrier formed by epithelial cells and penetrates into the underlying tissue, surrounding cells sense the pathogen and send signals that recruit neutrophils to the site of infection. Since neutrophils circulate in a ready-to-use state, influx into tissue can occur fast and exceedingly. ${ }^{16}$ Upon contact with invaded microbes, neutrophils fight pathogens in a well-orchestrated sequence of recognition, phagocytosis, intra- and extracellular toxification and local retainment. ${ }^{17}$

These functions are all facilitated by the unique morphology of neutrophils. The nucleus is lobulated, allowing the cell to squeeze through layers of tissue. High numbers of granules store antimicrobial peptides and proteins that can be either secreted into the surrounding of the neutrophils or into the phagolysosome. ${ }^{18}$ The latter is a highly inhospitable cellular compartment that retains the phagocytosed pathogen. Inside, the pathogen encounters not only antimicrobial peptides and proteins, but also low $\mathrm{pH}$ and reactive oxygen and nitrogen species. ${ }^{19}$ In addition to secretion and phagocytosis, neutrophils form also extracellular traps (NETs). ${ }^{20}$ During NET formation, the nuclear membrane followed by granule membranes and finally the cytoplasmic membrane lose integrity. This allows compartments to mix that are usually separated. NETs consist of DNA, histones, and cytoplasmic and granular proteins. ${ }^{21}$

Calprotectin is one of the NET effector proteins. ${ }^{22}$ It is the most abundant protein in the neutrophilic cytoplasm, usually not secreted by intact neutrophils, but released during NET formation. Calprotectin is crucial for the NETs efficacy towards bacterial and fungal pathogens, which is explained by its $\mathrm{Mn}$ and $\mathrm{Zn}$ chelating properties. ${ }^{22-25}$ It has been shown earlier that NET-mediated growth inhibition of Candida albicans and Aspergillus nidulans could be reversed by the addition of $\mathrm{Zn}$. Whether NET formation, a process of complete cell burst, actually reduces the availability of $\mathrm{Zn}$ for the fungal pathogen remains unexplored.

On these grounds, we aimed to elucidate the trace element properties of human neutrophils - resting and activated. To do so, we combined SR micro/nano-XRF, ICP-MS, and live cell imaging. The sample preparation for the SR-XRF measurements was adjusted to optimize the neutrophil analysis: in order to quantify whole neutrophils and analyze filamentous NETs with optimally preserved metal contents, entire cells were seeded on a $\mathrm{Si}_{3} \mathrm{~N}_{4}$ wafer and freeze-dried. To investigate neutrophils with the highest possible subcellular resolution and analyze intracellular metal concentrations, neutrophils were high-pressure frozen (HPF), cryosubstituted and sliced in $2 \mu \mathrm{m}$ thin sections. Using ICP-MS, we quantified neutrophil supernatants post NET formation and neutrophil full cell lysates for total metal content. Lastly, we investigated the distribution of labile $\mathrm{Zn}$ in living cells by applying the fluorophore Fluozin in activated neutrophils.

In summary, we successfully analyzed the trace element distributions of human neutrophils down to nanoscopic levels using SR-XRF complemented with ICP-MS and live cell imaging. While ICP-MS is a broadly used technique, reports of SR-XRF for analysis of biological samples are more scarce. ${ }^{26-28}$ To our knowledge, this is the first study to use SR-XRF at the microand nanoscopic level on individual innate immune cells. Earlier work included for instance single neurons and keratinocytes, but also a variety of other biological sample fluids, tissues and even whole small organisms like mussel larvae or the water flea. ${ }^{29-35}$ SR-XRF offers spatially resolved (down to $50 \mathrm{~nm}$ resolution) and quantitative insights (sub-ppm level) that can contribute to the in-depth understanding of the site of infection as a nutritional niche. The approach presented will be applicable and valuable to numerous aspects of nutritional immunity.

\section{Results}

\section{Trace-level metallome of human neutrophils determined by SR-XRF and ICP-MS}

High influx of neutrophils to the site of infection very likely affects the local metal environment. In this context, transition metals are particularly important for nutritional immunity. We measured the neutrophil suspension diameter as $8.85 \pm$ $0.44 \mu \mathrm{m}$ and, using this value, calculated the total cellular concentration of metal ions assuming an even spherical shape of the cells, resulting in a cell volume of approximately $363 \mu \mathrm{m}^{3}$. We used ICP-MS to analyze the neutrophil's total content of $\mathrm{Zn}$, $\mathrm{Fe}, \mathrm{Cu}$, and $\mathrm{Mn}$. Neutrophil lysates from $10^{7}$ cells per sample were conducted, resulting in the following metallome: Freshly isolated human neutrophils were found to contain $6.07 \pm 1.29 \times$ $10^{7} \mathrm{Zn}$ atoms, $1.64 \pm 0.33 \times 10^{8} \mathrm{Fe}$ atoms, $2.26 \pm 0.69 \times 10^{6} \mathrm{Cu}$ atoms, and $2.49 \pm 0.69 \times 10^{5} \mathrm{Mn}$ atoms (Table 1 ). The total cellular concentration was calculated similarly: $[\mathrm{Zn}]=275.31 \pm 58.61 \mu \mathrm{M}$, $[\mathrm{Fe}]=743.91 \pm 148.62 \mu \mathrm{M},[\mathrm{Cu}]=10.24 \pm 3.11 \mu \mathrm{M}$, and $[\mathrm{Mn}]=$ $1.13 \pm 0.31 \mu \mathrm{M}$ (Table 1).

Table 1 Total metal content of neutrophils determined by ICP-MS. Freshly isolated neutrophils from 8 healthy volunteers were alkaline lyzed and resulting lysates were quantified by ICP-MS. The average and standard deviation of all 8 biological replicates are displayed

\begin{tabular}{llc}
\hline Element & Atoms per cell & $\begin{array}{l}\text { Intracellular } \\
\text { concentration }(\mu \mathrm{M})\end{array}$ \\
\hline $\mathrm{Zn}$ & $6.07 \pm 1.29 \times 10^{7}$ & $275.31 \pm 58.61$ \\
$\mathrm{Fe}$ & $1.64 \pm 0.33 \times 10^{8}$ & $743.91 \pm 148.62$ \\
$\mathrm{Cu}$ & $2.26 \pm 0.69 \times 10^{6}$ & $10.24 \pm 3.11$ \\
$\mathrm{Mn}$ & $2.49 \pm 0.69 \times 10^{5}$ & $1.13 \pm 0.31$
\end{tabular}


To obtain information on the spatial distribution of tracelevel metals within neutrophils we scanned whole cells using micro/nanobeam SR-XRF, fitted the individual point spectra and generated the elemental maps. In addition to the information on spatial distribution, XRF was used to quantitatively determine the neutrophil metallome using an ICP-MS-independent method. The total XRF spectrum of a single neutrophil was obtained by region-of-interest selection and summing up the individual XRF spectra belonging to the single cell, followed by quantification of the cell sum spectrum using a glass trace-element calibration standard. Based on the measurements of three individual freeze-dried neutrophils, an average neutrophil was determined to contain $6.94 \pm 0.86 \times 10^{7} \mathrm{Zn}$ atoms, $9.38 \pm 1.11 \times 10^{6} \mathrm{Fe}$ atoms, $1.38 \pm 0.18 \times 10^{7} \mathrm{Cu}$ atoms, and $8.73 \pm 1.76 \times 10^{5} \mathrm{Mn}$ atoms (Table S1, ESI $\dagger$ ). Accordingly, the total cellular concentrations were calculated: $[\mathrm{Zn}]=317.35 \pm 39.17 \mu \mathrm{M},[\mathrm{Fe}]=$ $42.91 \pm 5.09 \mu \mathrm{M},[\mathrm{Cu}]=63.27 \pm 8.17 \mu \mathrm{M}$, and $[\mathrm{Mn}]=3.99 \pm$ $0.80 \mu \mathrm{M}$ (Table S1, ESI $\dagger$ ).

In comparison, the two different techniques resulted in partially different neutrophil metallomes. The determined concentration of cellular $\mathrm{Zn}$ was consistent between the two techniques. $\mathrm{Zn}$ is known to have total cellular concentrations of 0.1-0.5 mM, so both neutrophil concentrations determined are well in range with other mammalian cells ${ }^{12}$. SR-XRF-determined total metal contents were approximately 3 and 6-fold higher than those determined by ICP-MS for $\mathrm{Mn}$ and $\mathrm{Cu}$, respectively. Finally, the ICP-MS quantification of cellular Fe levels resulted in an approximately 17 -fold higher value than XRF. From this point on, we use and refer to the ICP-MS metallome, due to a higher statistical certainty - we used 8 different donors and $10^{7}$ cells per sample.

To test the hypothesis that neutrophils might be purposely low in metal ions to compensate for their high influx to infection sites, we included two other mammalian cells frequently used in molecular infection research: macrophage-like J774 cells and HeLa cells. Since both cells are larger than neutrophils, we were not surprised to find a higher total metal content for J774 and HeLa cells. In suspension, J774 cells have a diameter of $15.8 \mu \mathrm{m}$; HeLa cells have a diameter of $22 \mu \mathrm{m} .{ }^{36,37}$ Accordingly, the volumes of these cells differ greatly. The calculated volumes were $363 \mu \mathrm{m}^{3}, 2065 \mu \mathrm{m}^{3}$, and $5575 \mu^{3}$ for neutrophils, J774 and HeLa cells, respectively. When the metal content was normalized to cell volume, we found J774 cells to be slightly richer in $\mathrm{Zn}$ and $\mathrm{Cu}$, much richer in $\mathrm{Mn}$, and poorer in Fe. HeLa cells had a similar $\mathrm{Zn}$ and $\mathrm{Cu}$ density, slightly increased Mn content, and a lower level of Fe as well (Fig. 1). This data indicates that neutrophils are higher in Fe than the other two cell types analyzed.

Distribution of $\mathrm{P}, \mathrm{S}, \mathrm{Ca}, \mathrm{Zn}, \mathrm{Fe}, \mathrm{Cu}$, and $\mathrm{Mn}$ in human resting neutrophils (obtained at P06 beamline, PETRA III)

SR-XRF measurements were performed at the P06 Hard X-ray Microprobe (PETRA III, Hamburg, Germany) providing at the time of the measurement a beam size of $0.5 \mu \mathrm{m}$ (vert.) $\times 0.4 \mu \mathrm{m}$ (hor.) FWHM. The scanning step size was typically $1 \mu \mathrm{m}$ (compromise between covering a large area for NET visualization and sufficient resolution). Freshly isolated neutrophils were seeded

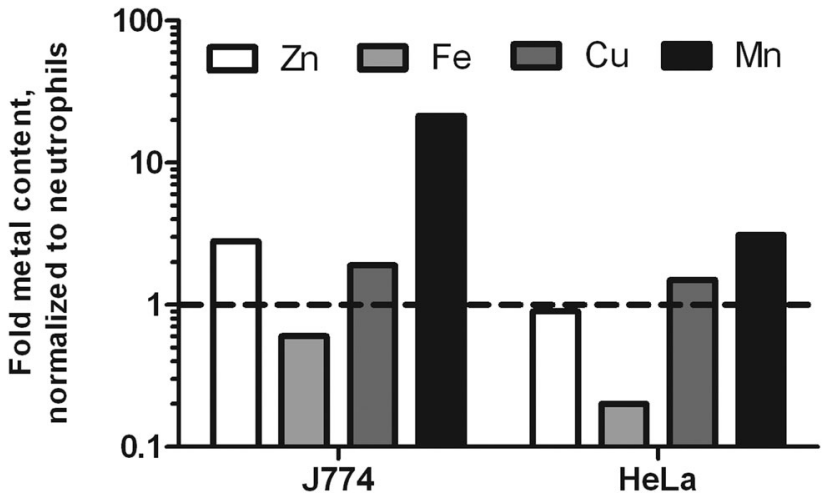

Fig. 1 Metallome comparison of human neutrophils with $\mathrm{J774}$ and HeLa cells. Cultured $\mathbf{J 7 7 4}$ and HeLa cells were alkaline lyzed and the resulting lysates were quantified by ICP-MS. The average content was related to the average content of human neutrophils, $n=3$, and normalized by cell volume, $n=3$.

onto $\mathrm{Si}_{3} \mathrm{~N}_{4}$ wafers, plunge-frozen in liquid ethane, and finally freeze-dried. Freeze-drying of whole cells was chosen to preserve elemental integrity - at expense of perfect morphology preservation; ${ }^{33}$ entire cells were analyzed in this 'whole-cell' set-up. Neutrophils of interest were selected based on their light-microscopic appearance and then analyzed by SR-XRF representative images are discussed in the following (Fig. 2a). Strikingly, the most prominent feature of neutrophils - the lobulated nucleus - stood out against the cytoplasm by an increased signal from $\mathrm{P}$ and $\mathrm{Zn}$. The cytoplasm displayed areal concentrations above background level for the elements $\mathrm{P}, \mathrm{S}$, $\mathrm{Zn}$, and Fe. Several potential contaminations were found, one of them in close proximity to the nucleus, slightly overlaying the neutrophil. In this and in randomly distributed 'speckles' on the entire sample, we detected $\mathrm{P}, \mathrm{S}, \mathrm{Ca}$, and Fe. To complement our observations, we aimed to quantify the trace element content of nucleus and cytoplasm. Since surface-attached neutrophils vary in thickness and total mass per area was not determined, average concentrations of metals in nucleus and cytoplasm could only be determined in approximation (Table S2, ESI $\dagger$ ). We found a higher average areal concentration of $\mathrm{Zn}$ and Fe in the nucleus as compared to the cytoplasm. Cu had a very low, but almost equal areal concentration in nucleus and cytoplasm (with the nucleus being thicker), while Mn was found to show higher areal concentrations in the cytoplasm.

Distribution of $\mathrm{P}, \mathrm{S}, \mathrm{Ca}, \mathrm{Zn}, \mathrm{Fe}, \mathrm{Cu}$, and $\mathrm{Mn}$ in activated human neutrophils and NETs (obtained at P06 beamline, PETRA III)

Similarly to the previous section ('whole-cell' set-up), freshly isolated neutrophils were seeded directly onto $\mathrm{Si}_{3} \mathrm{~N}_{4}$ wafers and stimulated with phorbol-myristate acetate (PMA) to induce ROS production, internalization events and NET formation. After $2 \mathrm{~h}$ and $4 \mathrm{~h}$, the samples were plunge-frozen and freeze-dried to preserve morphology. Unstimulated neutrophils were also included (see previous section). A $4 \mathrm{~h}$ stimulation with PMA is sufficient to cause a nearly full conversion of neutrophils to NETs. ${ }^{21,38}$ The $2 \mathrm{~h}$ stimulation represents an intermediate 
(a)
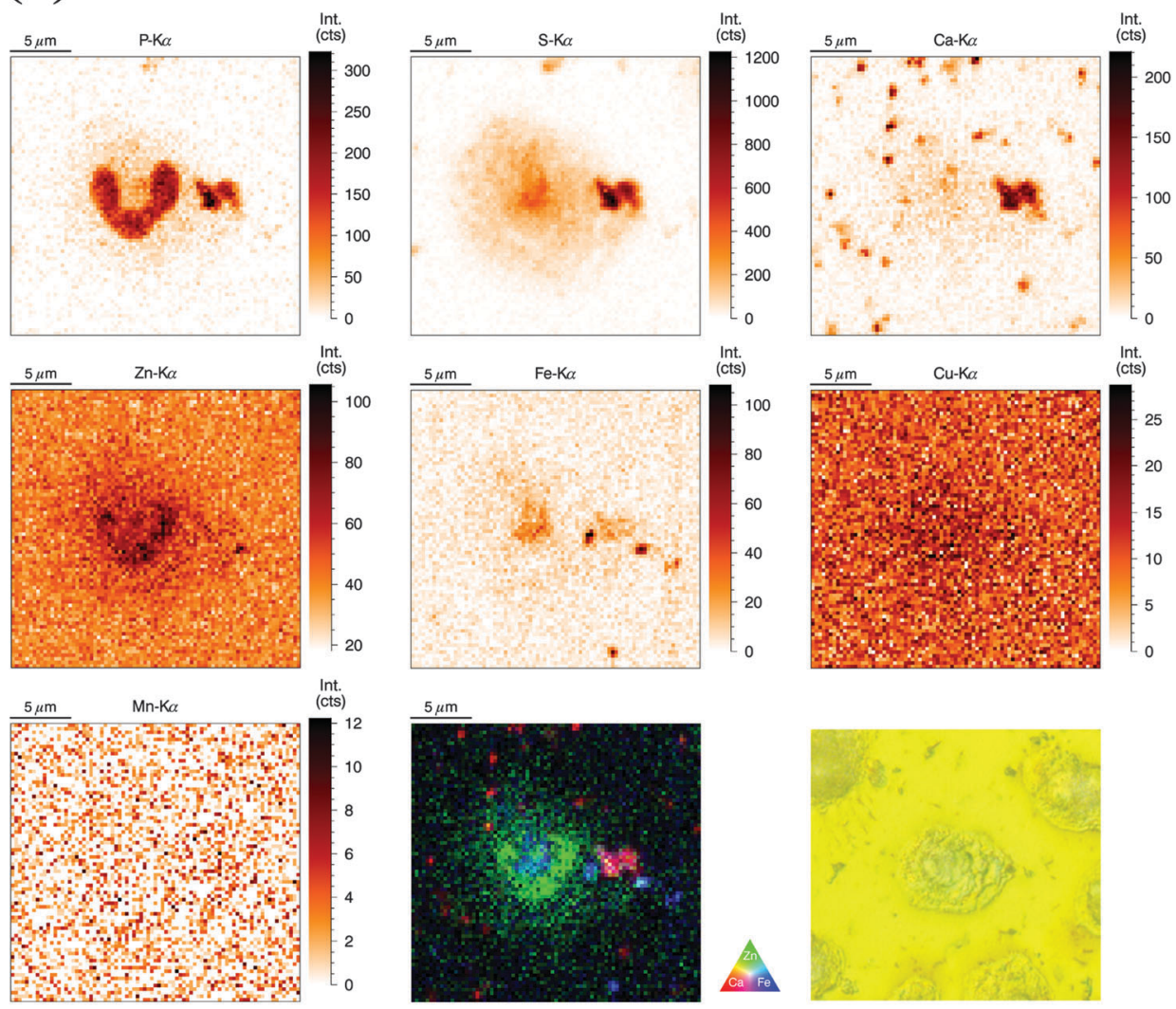

(b)
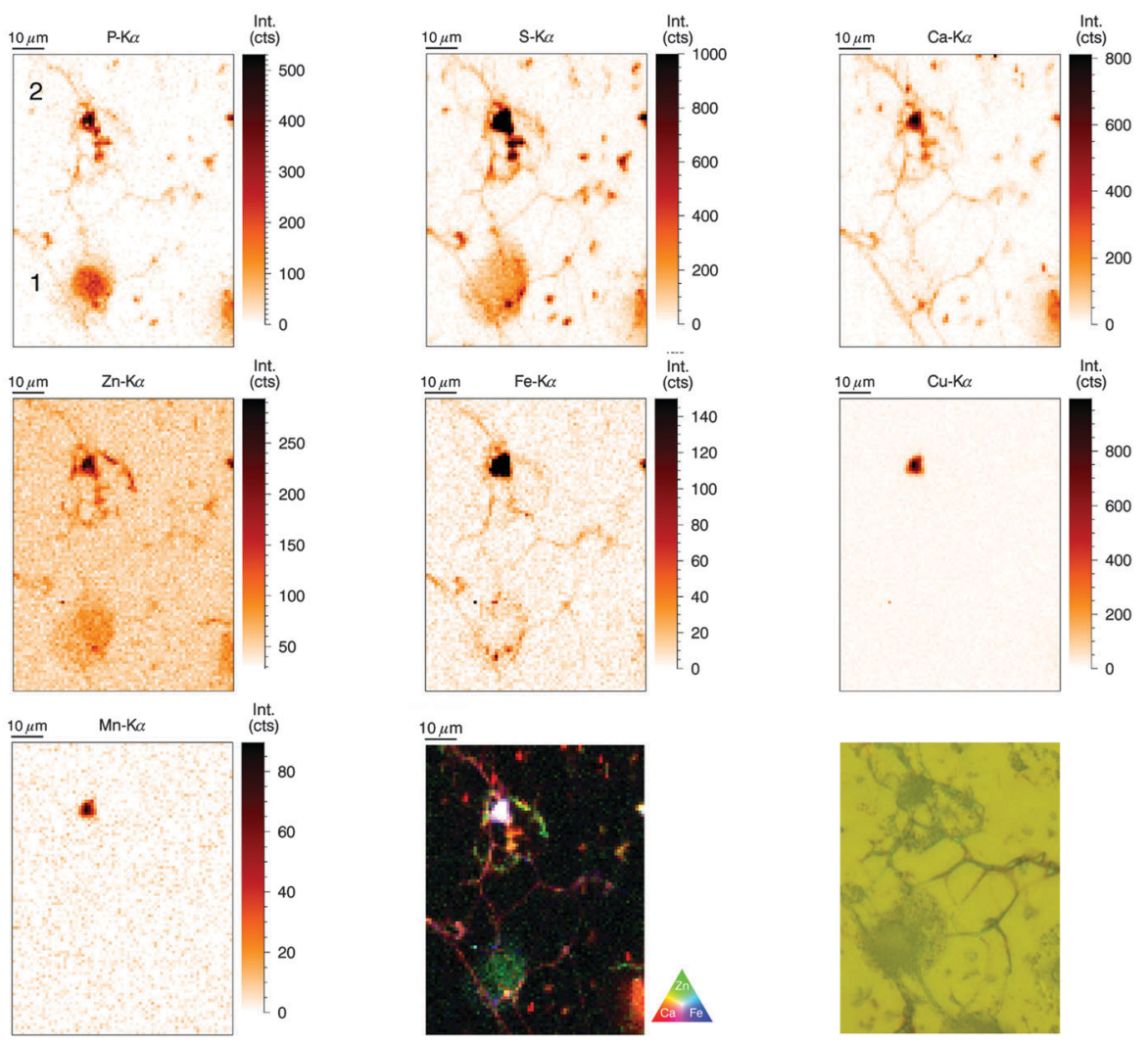
(c)
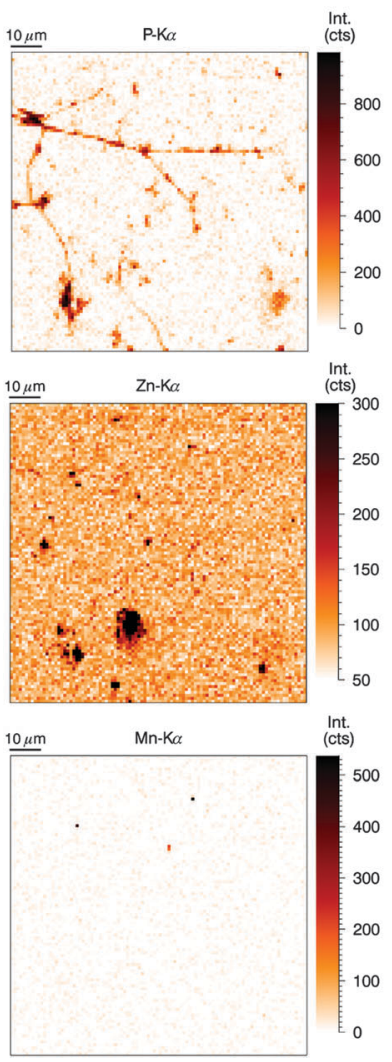
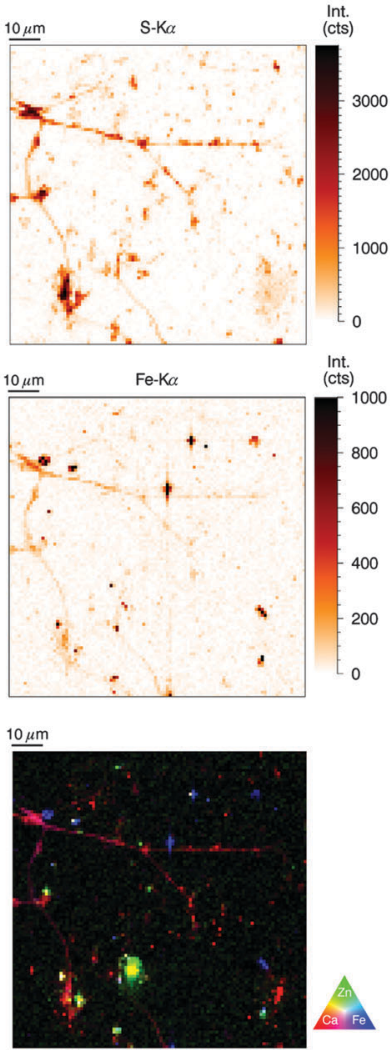
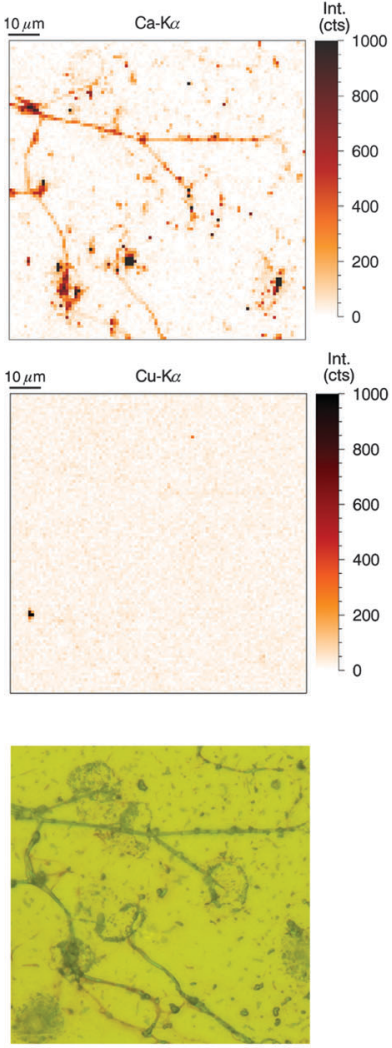

Fig. 2 (a) Normalized elemental distributions (P, S, Ca, Zn, Fe, Cu, and Mn) of a single resting human neutrophil obtained at P06 beamline (PETRA III, Hamburg). Freshly isolated neutrophils were seeded on a $\mathrm{Si}_{3} \mathrm{~N}_{4}$ membrane and subsequently freeze-dried. Image size is $81 \mu \mathrm{m} \times 78 \mu \mathrm{m}$, step size is $300 \mathrm{~nm}$ and $4 \mathrm{~s}$ dwell time per point. The RGB image represents a colored overlay of the elemental intensities corresponding to $\mathrm{Ca}$ (red) $-\mathrm{Zn}$ (green) and $\mathrm{Fe}$ (blue). An optical image was taken by the beamline microscope (2500 $\times$ magnification). (b) Normalized elemental distributions (P, S, Ca, Zn, Fe, Cu, and $\mathrm{Mn}$ ) of two activated human neutrophils ( $2 \mathrm{~h}$ stimulation) obtained at P06 beamline. Freshly isolated neutrophils were seeded on a $\mathrm{Si}_{3} \mathrm{~N}_{4}$ membrane, stimulated with PMA for $2 \mathrm{~h}$ and subsequently freeze-dried. Image size: $73 \mu \mathrm{m}$ (hor.) $\times 97 \mu \mathrm{m}$ (vert.), step size: $1 \mu \mathrm{m}$ and $5 \mathrm{~s}$ dwell time per point. The RGB image represents a colored overlay of the elemental intensities corresponding to $\mathrm{Ca}$ (red) $-\mathrm{Zn}$ (green) and Fe (blue). An optical image was taken by the beamline microscope ( $2500 \times$ magnification). (c) Normalized elemental distributions ( $\mathrm{P}, \mathrm{S}, \mathrm{Ca}, \mathrm{Zn}, \mathrm{Fe}, \mathrm{Cu}$, and Mn) of human neutrophils (4 h stimulation) obtained at the PETRA III P06 beamline. Freshly isolated neutrophils were seeded on a $\mathrm{Si}_{3} \mathrm{~N}_{4}$ membrane, stimulated with PMA for $4 \mathrm{~h}$ and subsequently freeze-dried. Image size: $100 \mu \mathrm{m} \times 100 \mu \mathrm{m}$, step size: $1 \mu \mathrm{m}$ and $3 \mathrm{~s}$ scanning time per point. The RGB image represents a colored overlay of the elemental intensities corresponding to $\mathrm{Ca}$ (red) $-\mathrm{Zn}$ (green) and Fe (blue). An optical image was taken by the beamline microscope (2500 $\times$ magnification).

stage (Fig. 2b). As mentioned, the analysis of unstimulated neutrophils revealed clear differences between the nucleus and the cytoplasm. After $2 \mathrm{~h}$ stimulation, the morphology of the neutrophils changed considerably, but not in a perfectly synchronized fashion. Some neutrophils engaged in the process of NET formation earlier than others. The progress of NET formation is most apparent when following the nucleus. In early NET formation, the nucleus loses its lobulation and shrinks to form a smaller and round shape (Fig. S3, * + a, ESI $\dagger$ ). The lower neutrophil \#1 is representative of this stage (Fig. 2b). As in unstimulated neutrophils, the nucleus contained a higher areal concentration of $\mathrm{P}$ and $\mathrm{Zn}$, whereas the cytoplasm featured a homogeneous distribution of $\mathrm{P}$ and $\mathrm{S}$ (higher areal concentration than background level). Interestingly, the intact stimulated neutrophil also showed the presence of an Fe rich region, distributed in a ring-like manner in the cell periphery. The upper neutrophil \#2 is representative of a later stage of NET formation, characterized by the loss of membrane integrity, first of the nucleus, then of the cytoplasmic membrane - the cell opens up and lyses (Fig. S3, b + c, ESI $\dagger$ ). When comparing the light microscope images of neutrophil $\# 2$ with neutrophil \#1, we observe that from the area initially covered by neutrophil \#1, only cell residues in neutrophil \#2 remain visible. The SR-XRF element maps confirm that the upper cell has likely lysed: Within the area of the cell (shape of an inverted heart or leaf), we could no longer observe the homogeneous distribution of $\mathrm{P}$ and $\mathrm{S}$. In contrast, the remaining cell debris was enriched in $\mathrm{P}, \mathrm{S}, \mathrm{Ca}, \mathrm{Fe}$, and $\mathrm{Zn}$. A hotspot containing not only these elements, but also $\mathrm{Cu}$ and $\mathrm{Mn}$ was found to lie within the area of neutrophil \#2. This is most likely a non-biological contamination. Short fiber-like structures, which we identified as NETs, are protruding out of the cell debris. Their areal concentrations for P, S, Zn, and Fe were found to be above background level. Similar to the unstimulated sample, several 'hot-spots' (1-4 $\mu \mathrm{m}$ size) containing $\mathrm{P}, \mathrm{S}$ and $\mathrm{Ca}$ are present which could be cell remnants. 
After $4 \mathrm{~h}$ of stimulation, NET formation was completed and no intact neutrophils were remaining (Fig. 2c). The typical orbital patches of cellular debris were as prominent as long filamentous fibers of NETs with a thickness at least below $1 \mu \mathrm{m}$ (estimation of size was limited by the chosen step size of the scanning stages). The SR-XRF analysis clearly showed the NET structure in the element maps of P, S, Ca and Fe. No strong accumulation of $\mathrm{Zn}$ could be detected in NETs, which is remarkable considering the high intracellular content of $\mathrm{Zn}$ in the neutrophil. This indicates that freshly releases NETs, under the given cell culture conditions with very low medium concentrations of $\mathrm{Zn}$, are not loaded with $\mathrm{Zn}$, yet. As mentioned, we observed high local $\mathrm{Ca}$ and Fe concentrations in NETs which were not detected within intact neutrophils. This finding correlates well with rather high concentrations of $\mathrm{Ca}(400 \mu \mathrm{M} \mathrm{Ca}$, according to manufacturer's information) and $\mathrm{Fe}(0.7 \mu \mathrm{M}$ according to ICP-MS quantification, data not shown) in the surrounding medium. Several $\mathrm{Ca}, \mathrm{Fe}$ and $\mathrm{Zn}$ rich spots having varying XRF intensity were detected in the vicinity of the NET structures. Consulting the microscopy images, these could be contaminations, cell debris or uneven twisting of numerous NETs from numerous neutrophils.

In summary, SR-XRF scans providing elemental distributions reconstitute the typical architecture of neutrophils at the microscopic level and allowed discrimination of nucleus, cytoplasm and far-reaching (up to $100 \mu \mathrm{m}$ ) NETs. Strikingly, cellular morphology changes accompanying NET formation and even NET filaments were visible in the element maps.

\section{Trace level metal distribution of nucleus and cytoplasm in resting neutrophils (obtained at ID22NI beamline, ESRF)}

For the analysis of human neutrophils at the ID22NI (nano-imaging) beamline (European Synchrotron Radiation Facility (ESRF), Grenoble, France), cells were seeded onto sapphire disks, conducted to high pressure freezing (HPF) and cryo-substituted into resin before being sliced into $2 \mu \mathrm{m}$ thin sections. We will refer to this as the 'sectioned' approach. In order to slice neutrophils at this scale, fixation and embedding were inevitable. ${ }^{31} \mathrm{We}$ minimized the procedure's impact on element integrity by including wash steps and reducing exposure time to potential contamination sources. The beam size was estimated to be $64 \mathrm{~nm}$ (vert.) by $54 \mathrm{~nm}$ (hor.) and the step size of the scans was $50 \mathrm{~nm}$. Images of representative cells are discussed in the following.

As observed before, the neutrophil nucleus stood out due to its distinct increase in metal content relative to the cytoplasm. Remarkably, the higher resolution revealed more subcellular detail than observed in the previous analysis (Fig. 3a). As a morphology reference, we used corresponding sections from the same sample imaged with transmission electron microscopy. The typical lobulated nucleus of an unstimulated neutrophil was distinguishable by increased areal concentrations of $\mathrm{P}, \mathrm{Ca}, \mathrm{Zn}$, $\mathrm{Fe}$, and Mn. These elements were not evenly distributed within the nucleus, but seemed to be more abundant in the outer region, closer to the nuclear membrane. The pattern is reminiscent of hetero- and euchromatin. Additionally, the Fe distribution showed round patches with increased Fe intensity, which might be nucleoli, the largest structures within the nucleus. Interestingly, $\mathrm{S}$ and $\mathrm{Cu}$ displayed an inverted pattern compared to the other elements: Lowest intensity in peripheral regions of the nucleus and presence in higher amounts within inner nuclear regions and cell cytoplasm. As we find both elements also in the surrounding matrix material, their presence in the cytoplasm must be considered very cautiously. Then again, a higher concentration of $\mathrm{S}$ in the cytoplasm is consistent with the high prevalence of reducing, S-containing, molecules and proteins in the cytosol. ${ }^{39}$ The presence of $\mathrm{Cu}$ in the neutrophil cytoplasm appears likely, as $\mathrm{Cu}$ is an essential trace element. ${ }^{4}$ In the periphery of the cells (at the edges of the scans), we observed a halo-like area of higher $\mathrm{S}$ and $\mathrm{Cu}$ concentration. This halo in the $\mathrm{S}$ and $\mathrm{Cu}$ maps very likely originates from $\mathrm{S}$ and $\mathrm{Cu}$ presence in the embedding resin. In areas with low biological mass, the beam-induced warm up of the samples probably caused the resin to shrink, and therefore locally increased the concentration of elements in the resin. In the cytoplasm, Ca was homogenously present, whereas Fe and $\mathrm{Zn}$ showed a speckled pattern, most probably resulting from neutrophil-characteristic granules loaded with antimicrobial proteins. The speckles had a average size of $200 \mathrm{~nm}$, which matches earlier studies that have shown granule size varying between $0.14 \mu \mathrm{m}$ and $0.29 \mu \mathrm{m} .{ }^{40}$ The $\mathrm{Zn}$ speckles were generally smaller in size than those formed by Fe. An overlay of the $\mathrm{Zn}$ and Fe elemental maps revealed that the granular speckles did not always co-localize, which indicates the presence of a variety of granules.

For our comparative analysis of nucleus and cytoplasm (Table 2), the speckles (potentially granular) or subnuclear structures were too small to be excluded. Since $2 \mu \mathrm{m}$ thin sections of single neutrophils were analyzed, the integration of the total illuminated mass signal of the entire cell depth along the beam path can be ruled out. Average areal concentrations of $\mathrm{P}, \mathrm{S}, \mathrm{Ca}, \mathrm{Zn}, \mathrm{Fe}, \mathrm{Cu}$, and $\mathrm{Mn}$ confirm our previous observation that most elements were preferentially enriched in nucleus or cytoplasm - only Fe seemed to be almost evenly distributed. In order to obtain quantitative insight in the inhomogeneous presence of metals in the nucleus as compared to the cytoplasm, we calculated a so-called 'enrichment factor': $\mathrm{P}(50.11 \times)>\mathrm{Zn}(3.19 \times)>\mathrm{Ca}(2.83 \times)>\mathrm{Mn}(3.98 \times)>\mathrm{Fe}$ $(1.29 \times)$. For the less abundant elements we found: $S(0.47 \times)<$ $\mathrm{Cu}(0.63 \times)$. In summary, this data indicate higher concentrations of $\mathrm{P}, \mathrm{Zn}, \mathrm{Ca}$, and $\mathrm{Mn}$, as well as lower concentrations of $\mathrm{S}$ and $\mathrm{Cu}$ in the nucleus as compared to the cytoplasm.

Clearly, the measurements at ID22NI allowed the detection and spatial analysis with higher sensitivity than SR-XRF measurements at PETRA III. The major differences between the two experiments and results in spatial distribution are mentioned in the text where appropriate and were additionally summarized in a comparing table (Table S4, ESI $\dagger$ ).

\section{Nanoscale elemental distributions of $\mathrm{P}, \mathrm{S}, \mathrm{Ca}, \mathrm{Zn}, \mathrm{Fe}, \mathrm{Cu}$, and $\mathrm{Mn}$ in activated human neutrophils (obtained at ID22NI beamline, ESRF)}

Similar to unstimulated cell preparations, cells were seeded on sapphire disks and, apart from PMA stimulation, prepared 
identically. However, more time points were included in order to relate cellular changes during activation and NET formation with differences in metal distribution.

Neutrophils activated for $1 \mathrm{~h}$ showed similar metal distributions of $\mathrm{P}, \mathrm{S}, \mathrm{Ca}, \mathrm{Zn}, \mathrm{Fe}, \mathrm{Cu}$ and $\mathrm{Mn}$ resulting in similar visibility of nucleus and cytoplasm (Fig. 3b). Fe speckles were again rougher and more dominant than $\mathrm{Zn}$ speckles present in the cytoplasm, and likewise low concentration of $\mathrm{Ca}$ could be detected in the cytoplasm. Interestingly, the cytoplasm of these briefly stimulated neutrophils revealed void vacuoles with visibly reduced concentrations of $\mathrm{Ca}, \mathrm{Fe}, \mathrm{Zn}$, and $\mathrm{Cu}$. Neutrophils are known to generate cytoplasmic membrane vacuoles upon strong stimulation. These vacuoles are formed by the internalization of extracellular liquid (pinocytosis) and show similarities to phagosomes. ${ }^{41}$ Thus, the low metal content in voids of PMA-stimulated neutrophils is consistent with the metal composition of phagosomes, membranesurrounded compartments which contain engulfed microbes and are also known to be low in $\mathrm{Zn}, \mathrm{Fe}$, and $\mathrm{Mn}^{7}$.

At $2 \mathrm{~h}$ and $3 \mathrm{~h}$ post stimulation, the morphology of the nucleus as well as its inner elemental distribution was altered tremendously (Fig. 3c and d). The lobulated shape of the nucleus disappeared and yet, enrichment of $\mathrm{Ca}, \mathrm{Mn}$, and $\mathrm{Zn}$ (a)
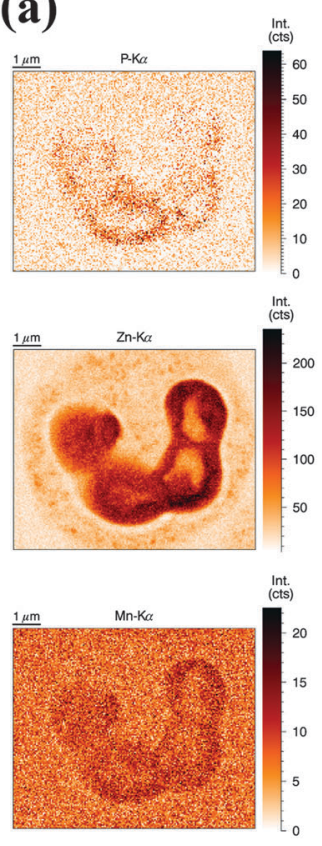

(b)
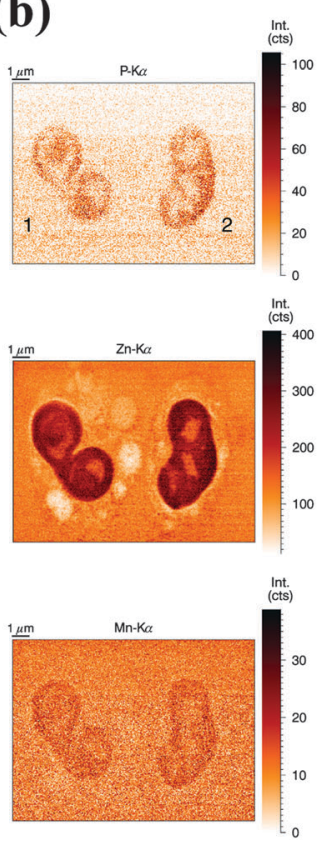
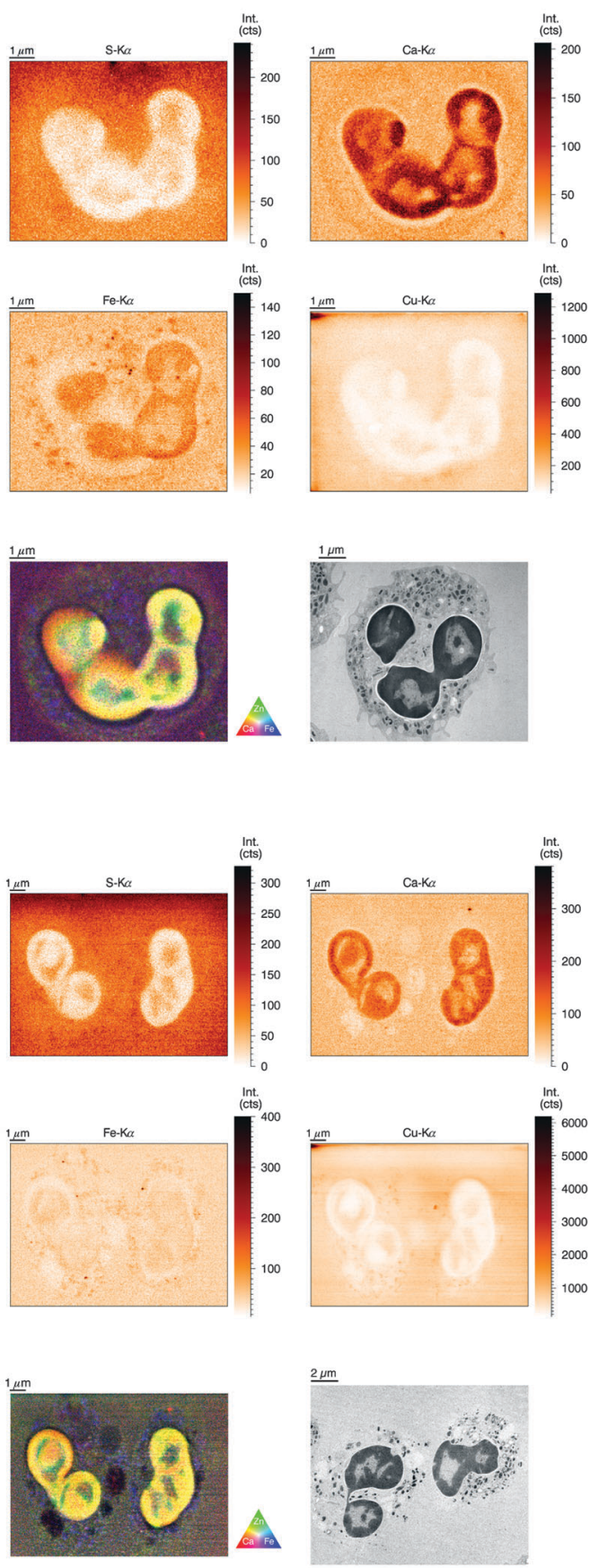
(c)
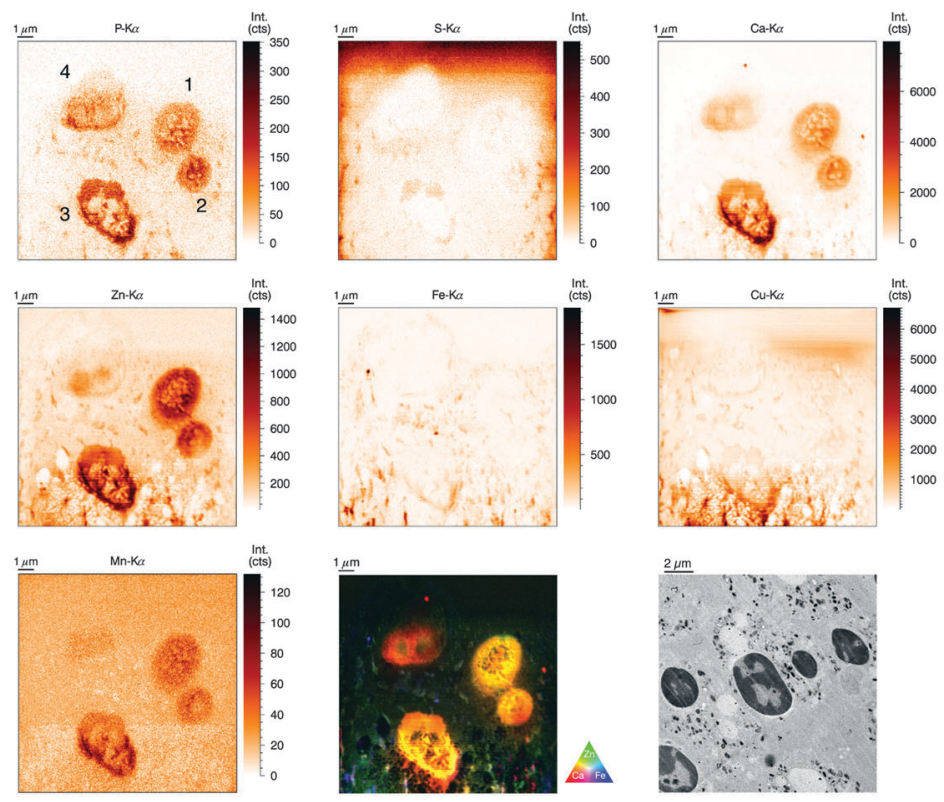

(d)

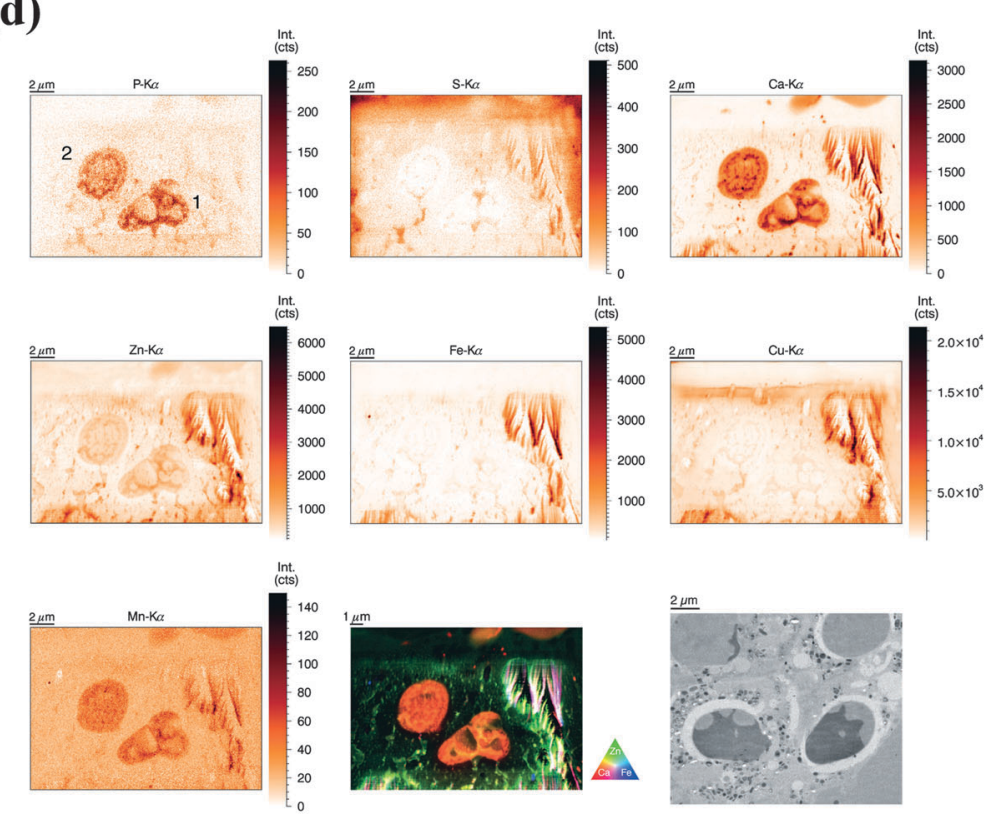

Fig. 3 (a) Normalized elemental distributions (P, S, Ca, Zn, Fe, Cu, and Mn) of a single resting human neutrophil obtained at ID22NI beamline (ESRF, Grenoble). Freshly isolated neutrophils were high pressure frozen, cryosubstituted in resin, sliced in $2 \mu \mathrm{m}$ thin sections before deposition onto a Si $\mathrm{N}_{4}$ wafer. Image area is $9 \mu \mathrm{m}$ (hor.) $\times 7.4 \mu \mathrm{m}$ (vert.), step size is $50 \mathrm{~nm}$ and $300 \mathrm{~ms}$ dwell time per point. The RGB image represents a colored overlay of the elements Ca (red) $-\mathrm{Zn}$ (green) and Fe (blue). The additional TEM image (lower right panel) was derived from the same sample and selected by similarity in morphology ( $10000 \times$ magnification). (b) Normalized elemental distributions ( $\mathrm{P}, \mathrm{S}, \mathrm{Ca}, \mathrm{Zn}, \mathrm{Fe}, \mathrm{Cu}$, and $\mathrm{Mn}$ ) of two activated human neutrophils ( $\mathrm{h}$ stimulation) obtained at ID22NI beamline (ESRF, Grenoble). Freshly isolated neutrophils were stimulated with PMA for $1 \mathrm{~h}$, high pressure frozen, cryosubstituted in resin and sliced in $2 \mu \mathrm{m}$ thin sections before deposition onto a $\mathrm{Si}_{3} \mathrm{~N}_{4}$ wafer. Image area is $15 \mu \mathrm{m}$ (hor.) $\times 11.2 \mu \mathrm{m}$ (vert.), step size is $50 \mathrm{~nm}$ and $400 \mathrm{~ms}$ dwell time per point. The RGB image represents a colored overlay of the elemental intensities corresponding to $\mathrm{Ca}$ (red) $-\mathrm{Zn}$ (green) and Fe (blue). The additional TEM image (lower right panel) was derived from the same sample and selected by similarity in morphology (2500 × magnification). (c) Normalized elemental distributions ( $\mathrm{P}, \mathrm{S}, \mathrm{Ca}, \mathrm{Zn}, \mathrm{Fe}, \mathrm{Cu}$, and Mn) of activated human neutrophils (2 h stimulation) obtained at ID22NI beamline (ESRF, Grenoble). Freshly isolated neutrophils were stimulated with PMA for $2 \mathrm{~h}$, high pressure frozen, cryosubstituted in resin, sliced in $2 \mu \mathrm{m}$ thin sections before deposition onto a Si $\mathrm{N}_{4}$ wafer. Image area is $15 \mu \mathrm{m}$ (hor.) $\times 15 \mu \mathrm{m}$ (vert.), step size is $50 \mathrm{~nm}$ and $300 \mathrm{~ms}$ dwell time per point. The RGB image represents a colored overlay of the elemental intensities corresponding to $\mathrm{Ca}$ (red) $-\mathrm{Zn}$ (green) and Fe (blue). The additional TEM image (lower right panel) was derived from the same sample and selected by similarity in morphology (2500× magnification). (d) Normalized elemental distributions (P, S, Ca, Zn, Fe, Cu, and $\mathrm{Mn}$ ) of activated human neutrophils ( $3 \mathrm{~h}$ stimulation) obtained at ID22NI beamline (ESRF, Grenoble). Freshly isolated neutrophils were stimulated with PMA for $3 \mathrm{~h}$, high pressure frozen, cryosubstituted in resin, sliced in $2 \mu \mathrm{m}$ thin sections before deposition onto a $\mathrm{Si}_{3} \mathrm{~N}_{4}$ wafer. Image area is $20 \mu \mathrm{m}$ (hor.) $\times 14 \mu \mathrm{m}$ (vert.), step size is $50 \mathrm{~nm}$ and $300 \mathrm{~ms}$ dwell time per point. The RGB image represents a colored overlay of the elements Ca (red) - Zn (green) and Fe (blue). The additional TEM image (lower right panel) was derived from the same sample and selected by similarity in morphology (2500× magnification). 
Table 2 Comparison and relation of areal concentrations in neutrophil nucleus and cytoplasm. Unstimulated neutrophils were analyzed individually by SR-XRF (ID22NI beamline, ESRF) and the areal concentration was determined and compared between nucleus and cytoplasm in $2 \mu \mathrm{m}$ thin slices. Trace-level metal content was determined using a NIST SRM 1577c standard for quantification. The average and standard deviation of three individual cells are displayed, as well as the corresponding mass-normalized 'enrichment factor' of the nucleus

\begin{tabular}{llll}
\hline Element & $\begin{array}{l}\text { Nucleus } \\
\left(\mu \mathrm{g} \mathrm{cm}^{-2}\right)\end{array}$ & $\begin{array}{l}\text { Cytoplasm } \\
\left(\mu \mathrm{g} \mathrm{cm}^{-2}\right)\end{array}$ & $\begin{array}{l}\text { Enrichment } \\
\text { factor }\end{array}$ \\
\hline $\mathrm{P}$ & $8.81 \pm 0.33 \times 10^{0}$ & $1.59 \pm 0.33 \times 10^{0}$ & $50.11 \pm 27.41$ \\
$\mathrm{~S}$ & $1.62 \pm 0.40 \times 10^{0}$ & $3.02 \pm 0.31 \times 10^{0}$ & $0.47 \pm 0.09$ \\
$\mathrm{Ca}$ & $8.80 \pm 0.58 \times 10^{-3}$ & $2.90 \pm 0.25 \times 10^{-3}$ & $2.83 \pm 0.26$ \\
$\mathrm{Zn}$ & $2.28 \pm 0.32 \times 10^{-3}$ & $6.84 \pm 2.11 \times 10^{-4}$ & $3.19 \pm 0.78$ \\
$\mathrm{Fe}$ & $1.14 \pm 0.15 \times 10^{-4}$ & $8.83 \pm 0.81 \times 10^{-5}$ & $1.29 \pm 0.18$ \\
$\mathrm{Cu}$ & $2.59 \pm 0.34 \times 10^{-3}$ & $4.04 \pm 0.35 \times 10^{-3}$ & $0.63 \pm 0.10$ \\
$\mathrm{Mn}$ & $2.40 \pm 0.19 \times 10^{-4}$ & $1.00 \pm 0.04 \times 10^{-4}$ & $3.98 \pm 0.10$
\end{tabular}

(and P) was still observed. The distribution of those elements within the nucleus however, was more homogenous than in nuclei from resting cells. This indicates that nuclei might have remained intact to this point, whereas separation of inner and outer nuclear region was lost. The cytoplasmic membrane, depicted by the $\mathrm{Zn}$ element map in resting cells, disappeared at these later stages. Even after a stimulation of $3 \mathrm{~h}$, void vacuoles characterized by the strongly reduced intensity of $\mathrm{Zn}$ and Fe were still present; at these stages in close proximity to the nuclei and smaller than during earlier stages.

Finally, after $4 \mathrm{~h}$ of stimulation, it was increasingly difficult to locate nuclei or whole cells (Fig. S5, ESI $\dagger$ ). The intensities in all elemental maps were close to the background level, probably caused by the cell burst spreading the intracellular content over a larger volume and therefore decreasing the areal element concentration. In summary, SR-XRF analysis with a spatial resolution at the $50 \mathrm{~nm}$ level revealed the element composition of neutrophil nucleus and cytoplasm and enabled detection of nuclear structures as well as cytoplasmic granules based on distinct element signals.

\section{Sample radiation damage and detection of NETs using SR-XRF}

We believe that the conditions for observing NETs in the high resolution (ID22NI) elemental maps starting from $2 \mathrm{~h}$ post activation are particularly challenging due to the following reasons. First of all, later stages of NET formation are accompanied by the loss of cell integrity, resulting in decreased areal concentrations of metals, resulting in higher signal-to-noise ratio. A second reason is the more pronounced sample radiation damage due to photo and auger electrons, depositing their energy locally. In Fig. 3d and Fig. S5 (ESI†), the sample radiation damage occurring in the embedding resin was surprisingly observed as a flame-like pattern, especially in the $\mathrm{Cu}$ map, of neutrophils stimulated for $3 \mathrm{~h}$ and $4 \mathrm{~h}$. Third, as the sections used in this experiment were only $2 \mu \mathrm{m}$ thick, NETs are sectioned in a random plane and therefore easily overlooked by $2 \mathrm{D}$ nano-XRF analysis, as their diameter would only encompass a few pixels, randomly located within the elemental map. Fourth, the scanning area of interest was defined by light microscopy, which is slightly biased in favor of visible and integer looking cells.

In contrast, conditions for observing NETs in the freezedried samples (beamline P06, PETRA III) scanned with $1 \mu \mathrm{m}$ step size were more favourable due to the following differences and changes: First, freeze-dried cells are denser than embedded cells resulting in less deposited energy and sample radiation damage. Second, deposition of the entire three-dimensional cell structure onto a two-dimensional wafer gathered all available NETs. And finally, the 'whole-cell' set-up increased the areal elemental concentrations of the sample allowing the beam to excite elements over the entire depth of the sample. Disadvantages are however the lower preservation of the ultrastructure and difficulties in comparing areal concentrations (Table S4, ESI $\dagger$ ).

In general, we can conclude that the combination of the two sample preparation approaches: 'whole cell' (freeze-dried whole cells analyzed at the microscale) and 'sectioned' (shock-frozen, embedded and sectioned cells) were crucial to meet the very different needs of resting and activated neutrophils and NETs.

\section{Presence of $\mathrm{Co}, \mathrm{Ni}, \mathrm{Sr}$, and $\mathrm{Pb}$ in human neutrophils}

It is a major advantage of SR-XRF compared to ICP-MS that it is unbiased regarding the investigated elements - no standard of individual elements is required prior to quantification. In agreement with this notion, we detected the elements $\mathrm{Co}, \mathrm{Ni}$, $\mathrm{Pb}$ and $\mathrm{Sr}$ which are less-well established as biologically relevant components (Fig. S6, ESI $\dagger$ ). $\mathrm{Co}, \mathrm{Ni}$, and $\mathrm{Pb}$ were accumulated in the nucleus and showed a distribution pattern similar to $\mathrm{Ca}$. In contrast, the concentration of Sr was only above background level near the cytoplasm border. While the presence of $\mathrm{Sr}$ in biological samples is expected - due to its chemical equivalence with $\mathrm{Ca}$ and accumulation in bone tissue - the presence and distribution of the other elements was less anticipated.

Secondary effects in X-ray fluorescence can often be a source for misinterpretation of results. In our case, a sudden increase in areal density of the sample (e.g. due to a more dense nucleus) could have caused a local increase in scattered photons, which may in turn generate additional fluorescence from the sample environment, potentially resulting in an increased signal above the expected value. However, we found little or no variation in the Compton scattering map, indicating that the areal mass throughout scanned area around the neutrophil is nearly constant. Therefore, even with a much higher presence of trace level metals in the nucleus, secondary effects erroneously enhancing the detection of these metals can be excluded in our case.

\section{Effects of NET formation on the availability of $\mathrm{Zn}, \mathrm{Fe}, \mathrm{Cu}$, and $\mathrm{Mn}$}

NETs inhibit growth of and kill microbes. The NET-mediated growth inhibition of the fungus Candida albicans can be overcome by the addition of $\mathrm{Zn}^{2+}$ to the medium. ${ }^{22}$ It is known that NETs contain calprotectin that chelates $\mathrm{Zn} .^{42}$ To verify whether NET formation indeed decreases the availability of $\mathrm{Zn}$, even though the entire cell opens up during this process, we analyzed the liquid and protein-filtered supernatant of NETs. Freshly isolated neutrophils were stimulated with PMA for $4 \mathrm{~h}$ in the 


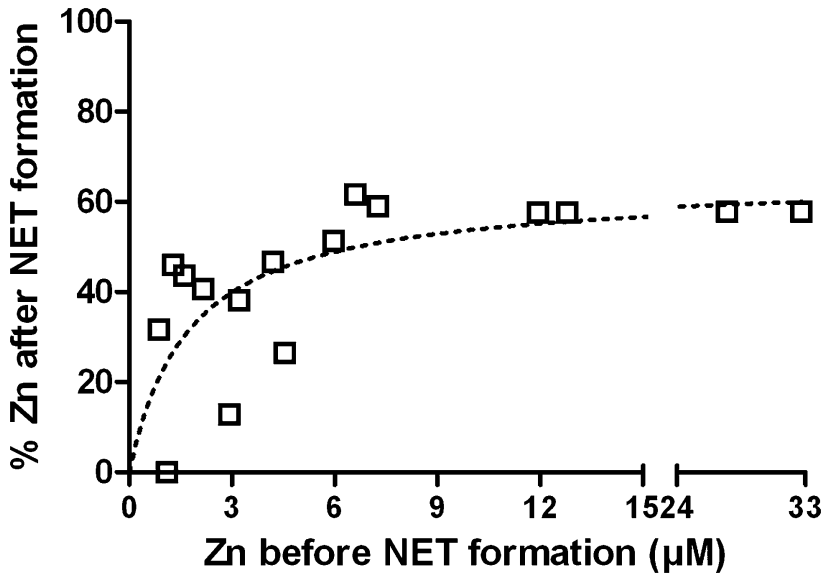

Fig. 4 NET-mediated reduction of Zn availability. NET formation was induced in neutrophils with PMA for $4 \mathrm{~h}$ in the presence of different $\mathrm{Zn}^{2+}$ concentrations. The remaining $\mathrm{Zn}$ concentration was quantified by ICP-MS. Pooled data from three independent ICP-MS experiments including samples from 8 healthy donors is shown.

presence of increasing $\mathrm{Zn}^{2+}$ concentrations up to $33 \mu \mathrm{M}$ and the $\mathrm{Zn}^{2+}$ concentration of the supernatant was quantified with ICP-MS before and after NET formation (Fig. 4). We found the remaining $\mathrm{Zn}^{2+}$ concentration to be depending on the initial $\mathrm{Zn}^{2+}$ concentration, following a saturation curve. With low initial $\mathrm{Zn}^{2+}$ concentrations up to $c a .6 \mu \mathrm{M}$, the resulting $\mathrm{Zn}$ concentration was in the range of $0-51 \%$ of the initial concentration. At initial concentration beyond this, the resulting concentration reached a maximum of approximately $63 \%$ (Fig. 4). We conclude that NET formation indeed reduces the availability of $\mathrm{Zn}$ and that there is specific binding at low to medium $(<3-6 \mu \mathrm{M})$ and unspecific association at high $\mathrm{Zn}$ concentrations $(>6 \mu \mathrm{M})$. We additionally measured $\mathrm{Fe}, \mathrm{Cu}$, and $\mathrm{Mn}$ concentrations before and after NET formation and detected only slight reductions of $9 \%, 5 \%$, and $7 \%$, respectively (Table S7, ESI $\dagger$ ).

\section{FluoZin-labeling of labile $\mathrm{Zn}$ pool during neutrophil activation}

The analysis of activated neutrophils using SR-XRF under routine conditions (i.e. without combining it with e.g. X-ray absorption spectroscopic techniques, XANES/EXAFS) is only providing element information. Therefore, distinguishing between strongly and loosely bound $\mathrm{Zn}$ is not possible. Strongly bound $\mathrm{Zn}$ exists in proteins of the $\mathrm{Zn}$ proteome, e.g. superoxide dismutase and ribosomes. Loosely bound $\mathrm{Zn}$, also called labile or "free" $\mathrm{Zn}$, is associated with all kinds of negatively charged molecules like DNA, organic acids or glutathione. ${ }^{12}$ An earlier study analyzing the distribution of "soluble" and "particulated" $\mathrm{Zn}$ in fractions of HepG2 cells found $65 \%$ of the $\mathrm{Zn}$ to be soluble and $35 \%$ to be in the pellet of a high-speed centrifuged cell extract. ${ }^{43}$ FluoZin can detect the labile $\mathrm{Zn}$ pool in living cells and was therefore used to complement our findings about the $\mathrm{Zn}$ distribution in neutrophils during activation and NET release. ${ }^{44}$ Fluozin-stained neutrophils were stimulated with PMA and followed by fluorescence-based live cell imaging over ca. $3 \mathrm{~h}$ (video V1, ESI $\dagger$ ). Four observations were most striking: First, the nucleus did not show a stronger fluorescence signal compared to the cytoplasm, indicating that the labile $\mathrm{Zn}$ is not higher concentrated in this organelle. Comparing this with the higher total areal $\mathrm{Zn}$ concentration in the nucleus observed with SR-XRF, we can deduce that most of the cellular $\mathrm{Zn}$ is strongly bound and present in the nucleus. Second, void vacuoles with low metal content, which were indicated by SR-XRF, were also visualized by FluoZin-labeling, confirming the low $\mathrm{Zn}$ content of these membrane-surrounded vesicles. Third, small round organelles high in labile $\mathrm{Zn}$ exclusively appeared after stimulation. We cannot distinguish at this point what type of intracellular vesicles these are. They also partially remained in the typical cell residues left after full NETosis and could therefore additionally contribute to the reduced $\mathrm{Zn}$ level after NET formation (Fig. 4). Lastly, major reshaping of the intracellular architecture occurred when the cells opened up just before NET release. Once this happened, the evenly distributed intracellular labile $\mathrm{Zn}$ disappeared, probably because $\mathrm{Zn}$ was diluted into the low-Zn medium. As expected, NETs were not visible in this setting. The cell culture medium used contained very low concentrations of $\mathrm{Zn}$ to avoid background fluorescence, and NETs were probably not saturated with $\mathrm{Zn}$ under these conditions. Similar effects were also seen with strongly bound $\mathrm{Zn}$ in the SR-XRF images from PETRA III (Fig. 2b and c).

Altogether, by Fluozin-labeling we were able to follow the major morphological changes in activated neutrophils up to final NET release visualizing the labile $\mathrm{Zn}$ pool. In contrast to SR-XRF, where Zn showed a higher total $\mathrm{Zn}$ areal concentration in the nucleus, FluoZin-imaging of free $\mathrm{Zn}$ indicates a homogenous distribution of the labile $\mathrm{Zn}$ pool in nucleus and cytoplasm.

\section{Discussion}

Neutrophils patrol in circulation, quickly invade a site of infection in high numbers, and fulfill their antimicrobial task until they reach cell death. The neutrophil life time is limited, since their weaponry is too dangerous for the host's own tissue to be stored for too long. Apoptosis and NETosis are two important cellular death mechanisms of neutrophils. During NETosis, the entire neutrophil opens up to release its intracellular content. During apoptosis, the cell stays surrounded by an intact membrane and is eventually removed by efferocytosis. A high influx of neutrophils into the infectious site, where individual neutrophils end their life by either NETosis or apoptosis, serves to remove the threat of invading microbes on the one hand, but probably also delivers a sudden nutritional enrichment of the infection niche. On these grounds, we performed an in-depth analysis of the trace element landscape of human neutrophils. By applying SR-XRF for the first time on single neutrophils, we obtained trace element distributions in resting and activated neutrophils undergoing pinocytotic events, intracellular rearrangements and NETosis. We were able to detect intracellular structures at the size of cytoplasmic granules $(\approx 200 \mathrm{~nm}$ ) and thin filamentous NETs (below $1 \mu \mathrm{m}$ diameter, up to $100 \mu \mathrm{m}$ length). We identified the lobulated nucleus and subnuclear structures, compared element distributions of nucleus and cytoplasm and followed neutrophil activation 
in a time course until ultimately NETs were released. We quantified the total content of biologically relevant metals ( $\mathrm{Zn}, \mathrm{Fe}, \mathrm{Cu}, \mathrm{Mn}$ ) of neutrophil lysates by ICP-MS and compared the resulting metallome with intact neutrophils analyzed by SR-XRF. The neutrophil metallome was further compared to macrophage-like J774 cells and HeLa cells revealing a cell type-specific composition of $\mathrm{Zn}, \mathrm{Fe}, \mathrm{Cu}$, and $\mathrm{Mn}$ with an exceptionally high Fe content. In addition, we experimentally demonstrated a specific reduction of available $\mathrm{Zn}$ by the process of NETosis. Finally, we visualized (1) the homogenously distributed labile $\mathrm{Zn}$ pool in activated neutrophils by Fluozin implying a nucleus mainly containing strongly bound $\mathrm{Zn}$ resulting from the high $\mathrm{Zn}$ areal concentration maps in SR-XRF, and (2) the presence of 'void' vacuoles - low in metal content - using FluoZin and SR-XRF in living and fixed cells respectively. Void vacuoles share features with the early phagosome, since they are also derived from pinocytosis, the uptake of extracellular liquids. ${ }^{7,41}$

Our metallome analysis of neutrophils in comparison to other mammalian cells commonly used in in vitro infection studies indicated a high Fe content in this cell type. This is also reflected by the ratios of the respective metals. For HeLa cells, were determined the following ratios: $\mathrm{Zn} / \mathrm{Fe} 2.0, \mathrm{Zn} / \mathrm{Cu} 16.7$, and $\mathrm{Fe} / \mathrm{Cu}$ 8.3. For macrophage-like $\mathrm{J} 774$ cells, the ratios were notably different: $\mathrm{Zn} / \mathrm{Fe} 1.8, \mathrm{Zn} / \mathrm{Cu} 40.2$ and $\mathrm{Fe} / \mathrm{Cu} 21.9$. The ratios of metals in neutrophils were even more distinct: $\mathrm{Zn} / \mathrm{Fe}$ 0.4, $\mathrm{Fe} / \mathrm{Cu} 72.6$, and $\mathrm{Zn} / \mathrm{Cu}$ 26.9. Earlier quantifications of 7 different cell culture lines by total reflection XRF (T-XRF) demonstrated that the ratio of cell metals can differ from cell line to cell line, resulting in a range of ratios. ${ }^{43}$ The cell lines investigated originated from different tissues and mammals. Primary immune cells were not included. Tapia et al. compared the concentration of $\mathrm{Fe}, \mathrm{Cu}$, and $\mathrm{Zn}$ in pelleted cells normalized to the protein mass and determined the range of metal ratios to describe the metal composition: $\mathrm{Zn} / \mathrm{Fe} 1.4-2.4$, $\mathrm{Zn} / \mathrm{Cu} 5.5-21.1$, and finally $\mathrm{Fe} / \mathrm{Cu}$ 3.0-12.3. Mn was not considered in this study.

A comparison to these findings confirms that neutrophils are very high in iron and rather low in $\mathrm{Cu}$. Macrophage-like J774 cells are low in $\mathrm{Cu}$, and according to our data richer in $\mathrm{Mn}$ than neutrophils. HeLa cells are closest to the types of cells analyzed by Tapia et al. - and their metal ratios are indeed completely in agreement with the ratios described. A possible explanation for the very high Fe content of human neutrophils is the high abundance of the enzyme myeloperoxidase (MPO), up to $5 \%$ of the cell mass. ${ }^{45}$ It contains a heme cofactor and produces hypochlorous acid during the oxidative burst. Additionally, neutrophils and also macrophages contain the heme-containing enzyme catalase that is used to protect against oxidative damage. Lastly, the relative low Mn content of neutrophils could result from the low number of mitochondria in these cells. ${ }^{46}$ All together, these values demonstrate nicely that the metal content of neutrophils is cell type specific.

Our SR-XRF analysis revealed that typical morphological features of neutrophils are also reflected in the spatial distribution of elements. The most striking features of resting neutrophils were the lobulated nucleus and speckles that we identified as granules. Those granules were enriched in Fe and $\mathrm{Zn}$, and the signal from both elements did not overlap completely. Indeed, neutrophils contain a number of different granules with partially distinct and partially overlapping content. ${ }^{18}$ Interestingly, the enzyme myeloperoxidase (MPO) is exclusively present in so-called azurophil granules and contains a heme cofactor, ${ }^{45}$ while neutrophil matrix metalloproteases are present in so-called specific granules, and both MMP8 (collagenase) and MMP9 (gelatinase B) are Zn-dependent. Iron-binding lactoferrin is also found in specific granules, but since lactoferrin is secreted to sequester iron, it is unlikely already loaded with $\mathrm{Fe}$ in the granules. ${ }^{8}$

In NETs on the other hand, lactoferrin is exposed to the extracellular environment. It is therefore likely that lactoferrin bound to NETs can chelate some Fe from the surrounding. In our study, we found that the Fe concentration in the supernatant of NETs was slightly decreased and we observed that NETs were enriched in $\mathrm{Ca}$ and $\mathrm{Fe}$. The high content of $\mathrm{Fe}$ in NETs is probably originating not only from lactoferrin, but also from the heme-containing enzymes MPO and catalase, as they are also known to be bound to NETs. ${ }^{22,47}$ Calprotectin is part of the NETome as well. This protein can bind $\mathrm{Ca}$, and on other binding sites $\mathrm{Zn}$ and $\mathrm{Mn} .{ }^{42}$ It is most likely responsible for the reduction of available $\mathrm{Zn}$ in the supernatant of NETs. Zn chelation by NETs is important towards fungal pathogens. This is illustrated by the inability of other metal ions than $\mathrm{Zn}^{2+}$ to rescue Aspergillus nidulans ${ }^{23}$ and Candida albicans (data not shown) from NET-mediated growth inhibition.

These findings shape the view on the nutritional immunological importance of neutrophils: Compared to other cells, the neutrophil is exceptionally high in Fe. This is likely the result of a high MPO content in neutrophil granules, which matches our findings of Fe speckles in the cytoplasm of neutrophils. Other metalcontaining enzymes in neutrophil granules are Zn-dependent metalloproteases. While these enzymes are released by activated neutrophils, we did not find an increased Fe or Zn concentration in the supernatant of activated neutrophils. On the contrary, we found the $\mathrm{Zn}$ concentration to be reduced and the Fe concentration to be almost unaffected. The analysis of NETs confirmed their capacity to bind Zn. Further, void vacuoles were found in activated neutrophils that were low in Fe and $\mathrm{Zn}$. Void vacuoles are likely similar to the early phagosome.

Our findings shape the view that neutrophils are capable of starving microbial pathogens intra- and extracellularly from key metal nutrients such as $\mathrm{Zn}$ and $\mathrm{Fe}$, remarkably even if they release metal-containing proteins by bursting open during NETosis. Due to the detection limitations and their lower abundance, we could not conclusively follow $\mathrm{Mn}$ and $\mathrm{Cu}$. Our data indicates though that void vacuoles are also low in $\mathrm{Cu}$. On these grounds, it would be worthwhile to investigate whether microbial pathogens target secreted or NET-released metal containing proteins as micro nutrient sources. An interplay similar to that of Fe in other settings seems very plausible. ${ }^{8}$

In addition to $\mathrm{Zn}, \mathrm{Fe}, \mathrm{Cu}$, and $\mathrm{Mn}$, we also detected a group of metals that are less renowned for their biological function or mostly described for their toxicity: $\mathrm{Co}, \mathrm{Ni}, \mathrm{Pb}$, and Sr. All metals besides $\mathrm{Sr}$ were found to be enriched in the nucleus of neutrophils; $\mathrm{Sr}$ was present at higher concentration in the cytoplasm. Interestingly, $\mathrm{Ca}$, which behaves very similar to $\mathrm{Sr}$, 
was enriched in the nucleus, and showed lower abundance in the cytoplasm. Due to the similarities of $\mathrm{Ca}$ and $\mathrm{Sr}, \mathrm{Sr}$ accumulates in bones of exposed humans. Co is an essential trace element, but also toxic at high concentrations. It is only found in humans as part of the cofactor cobalamin or vitamin B12 (VitB12), which is exclusively produced by commensal bacteria in the gastro-intestinal tract. Amongst the small number of VitB12-binding proteins in humans, transcobalamin I was identified in neutrophils. ${ }^{48}$ The protein is localized in secondary granules and can be secreted to bind VitB12. Thus, transcobalamin I is not necessarily saturated with VitB12 in the granules. To our knowledge, no nuclear cobalamin-containing enzymes have been described, yet. Nevertheless, it was shown that human keratinocytes for instance accumulate Co in the nucleus and perinuclear areas. ${ }^{32} \mathrm{Ni}$, one of the most toxic of these metals, has no known biological function in eukaryotes, but is found in a variety of prokaryotic enzymes. $\mathrm{Pb}$ is a known environmental pollutant that accumulates in our bodies in many organs, most persistently in the bones. Notably, all 4 elements have been detected in whole blood of healthy individuals that were considered "free of exposure" to any heavy metal contamination. ${ }^{49,50}$ Since the majority of all white blood cells are neutrophils, it seems reasonable to assume that neutrophils contributed to this detection in whole blood. As all blood cells are generated in the bone marrow, neutrophils are unlikely the only blood cells to contain $\mathrm{Co}, \mathrm{Ni}, \mathrm{Pb}$, and $\mathrm{Sr}$. In conclusion, we have detected $\mathrm{Co}, \mathrm{Ni}, \mathrm{Sr}$, and $\mathrm{Pb}$ in isolated neutrophils from two individuals living under supposedly non-exposed conditions. This data indicates an accumulation of $\mathrm{Co}, \mathrm{Ni}$, and $\mathrm{Pb}$ in the nucleus, whereas $\mathrm{Sr}$ is present in the vicinity of the outer cell membrane in unstimulated neutrophils.

In the present study, we used two different approaches for SR-XRF with their respective benefits and disadvantages: Sectioned samples analyzed at nanoscopic resolution allowed us to have highly detailed insights into intact neutrophils and compare the areal concentration in nucleus and cytoplasm. In contrast, the microscopic-scaled 'whole-cell' approach enabled us to quantify the neutrophil metallome and analyze element distributions of neutrophils forming NETs (both intermediate and final stages of NETosis). Substantial benefits of SR-XRF are (1) the extreme sensitivity, with the potential of single atom detection at future nano-beam facilities for transition metals; (2) the minimal sample preparation required: cells do not need to be lyzed and diluted - factors that might affect the reliability in any other way than the final fixation; (3) the potentially nondestructive character: under right measuring conditions samples can be stored and re-analyzed at later periods; and (4) the spatial information: individual cells meeting all requirements can be selected and analyzed with submicron resolution. Artifacts influencing the determined metal distributions are therefore, assuming an appropriate sample preparation method and experimental design, rather unlikely. As described, we utilized SR-XRF to determine the neutrophil metallome to complement our measurement using ICP-MS. Due to the time consuming character of SR-XRF, we only analyzed three individual cells, whereas for ICP-MS each sample contained $10^{7}$ neutrophils. This is, together with the distinct sample preparations, most likely the major reason for the deviations between the results of the two different methods. Moreover, uncertainties in calibration and interfering background signals are factors which might influence Fe concentration measurement using SR-XRF. Quantification of Fe by ICP-MS on the contrary, might be hampered by spectral interferences.

Nevertheless, the usage of SR-XRF in actual in vitro infections or sections from in vivo infection (e.g. as tissue sections) seems very promising. Earlier studies have demonstrated, for instance, the cellular reduction of Fe and $\mathrm{Zn}$ in Histoplasma-infected macrophages $^{51}$ or the specific enrichment of $\mathrm{Cu}$ in the phagolysosome containing Mycobacteria. ${ }^{52}$ These and similar phenomena are ideal candidates for SR-XRF analysis at the nanoscale - adding new information about elemental distribution and concentrations. Meticulously describing the trace element composition during different stages of infection within affected organs might even identify new targets for antimicrobial therapy. Trace elements are essential for microbial growth and their removal could be a potential treatment for infections. The lack of certain metals cannot be easily overcome by mutagenesis leading to resistance, which makes it a promising target for further research.

\section{Materials \& methods}

\section{Chemicals and solutions}

Unless stated otherwise, chemicals and solutions were purchased from Sigma-Aldrich.

\section{Isolation of neutrophils from venous blood}

Neutrophils were isolated from human venous blood by using an isolation technique that combines separation on Histopaque1119 (Sigma-Aldrich) and Percoll (GE Healthcare). Venous blood from human donors was received upon fully informed written consent according to the guidelines of the local ethical committee (Regionala etikprövningsnämnden i Umeå). Briefly, fresh blood was layered in a 1:1 ratio on top of Histopaque-1119, followed by centrifugation at $800 \times g$ for $20 \mathrm{~min}$. The resulting white-blood-cell containing phase was demounted and cells were washed by adding 5-6-fold volume of PBS with $0.5 \%$ human serum albumin (HSA). Cells were pelleted by centrifugation for $5 \mathrm{~min}$ at $300 \times g$. The cell pellet was resuspended and applied onto a discontinuous gradient of phosphate-buffered Percoll with the concentrations $85 \%, 80 \%, 75 \%, 70 \%$ and $65 \%$. Cell separation occurred on the gradient during centrifugation at $800 \times g$ for $20 \mathrm{~min}$. Cells accumulated at the interphase between $75 \%$ and $70 \%$ were collected and washed as described before. Finally, cells were taken up in RPMI medium (Lonza).

\section{Neutrophil lysate preparation for ICP-MS}

Freshly isolated neutrophils from 8 different healthy donors were lyzed. For each sample, $10^{7}$ neutrophils were taken up in $100 \mu \mathrm{l}$ HEPES-buffered RPMI and NaOH (99.99\% metals basis, semiconductor grade) was added to reach $0.25 \mathrm{M}$ in $200 \mu \mathrm{l}$. This mixture was incubated for $2 \mathrm{~h}$ at $65{ }^{\circ} \mathrm{C}$ with vigorous shaking. Subsequently, lysates were sonicated for $1 \mathrm{~h}$ in a sonification bath. 
Samples were stored at $-20{ }^{\circ} \mathrm{C}$ up to further use. J774 cells $\left(9 \times 10^{6}\right)$ and HeLa cells $\left(5 \times 10^{6}\right)$ were handled accordingly. A biological replicate was therefore either a different blood donor or a different flask and passage of the cultured cells.

\section{NET supernatant preparation for ICP-MS}

Neutrophils were diluted in HEPES-buffered RPMI with or without supplementation of different concentrations of $\mathrm{Zn}$ sulfate (99.999\% metals basis). To avoid variations, RPMI from only one batch was used for all sample preparations for ICP-MS. Into each well of a 24-well plate, $500 \mu \mathrm{l}$ cell suspension containing $10^{6}$ cells were seeded and then stimulated with $100 \mathrm{nM}$ PMA (Sigma-Aldrich). NET formation occurred during a $4 \mathrm{~h}$ incubation at $37{ }^{\circ} \mathrm{C}$ with $5 \% \mathrm{CO}_{2}$. After this, $400 \mu \mathrm{l}$ of the supernatant were harvested and cell debris was pelleted by centrifugation for $10 \mathrm{~min}$ at $21000 \times$ g. $300 \mu \mathrm{l}$ of the supernatant were transferred onto a Vivaspin-500 centrifugal column (Sartorius) with a molecular weight cut-off of $3 \mathrm{kDa}$ (corresponding $\mathrm{ca} .27$ amino acids). The supernatants were filtered by centrifugation for $30 \mathrm{~min}$ at $10000 \times$ $g$ at $4{ }^{\circ} \mathrm{C} .200 \mu \mathrm{l}$ of the flow through were collected into new reaction tubes and stored at $-20{ }^{\circ} \mathrm{C}$ for further use.

\section{ICP-MS measurement}

The concentrations of trace metals were determined with inductively coupled plasma mass spectrometry (ICP-MS, PerkinElmer/Sciex Elan DRC-e instrument) operated in reaction cell mode with $0.6 \mathrm{ml} \mathrm{min}{ }^{-1}$ oxygen and an RPq-value of 0.45. The instrument was equipped with a microconcentric PFA nebulizer (Elemental Scientific Inc.) combined with a quartz cyclonic spray chamber (Elemental Scientific Inc.) set to $4{ }^{\circ} \mathrm{C}$. A nebulizer gas flow rate of $0.661 \mathrm{~min}^{-1}$ and a plasma RF power of $1200 \mathrm{~W}$ were used. The ${ }^{55} \mathrm{Mn},{ }^{56} \mathrm{Fe},{ }^{57} \mathrm{Fe},{ }^{63} \mathrm{Cu},{ }^{65} \mathrm{Cu},{ }^{64} \mathrm{Zn},{ }^{66} \mathrm{Zn}$ and ${ }^{68} \mathrm{Zn}$ isotopes were monitored with a dwell time of $50 \mathrm{~ms}$ and a total measurement time of $1 \mathrm{~min} 48 \mathrm{~s}$. The obtained isotope distributions were compared with the theoretical patterns to verify the absence of spectral interferences. Quantification was done by external calibration using indium (monitoring isotope ${ }^{115} \mathrm{In}$ ) as internal standard. Sample solutions were typically diluted 40 times with Milli-Q water ( $>18 \mathrm{M} \Omega \mathrm{cm}$, Milli-Q Advantage A10 Ultrapure Water Purification System, Merck Millipore) containing $1 \% \mathrm{HNO}_{3}$ prior to analysis.

\section{Sample preparation for beamline P06, PETRA III}

Neutrophils were seeded directly on a $5 \times 5 \mathrm{~mm}^{2}$ silicon nitride window (Silson Ltd, Northampton, UK, $1.5 \times 1.5 \mathrm{~mm}^{2}$ membrane size, $200 \mathrm{~nm}$ membrane thickness). $5 \times 10^{3}$ cells were added in a $10 \mu$ l drop of HEPES-buffered RPMI and NET formation was induced with $100 \mathrm{nM}$ PMA. Incubation occurred as described earlier. After the incubation, cells were washed very briefly with ultraclean $\mathrm{H}_{2} \mathrm{O}$ and plunge-frozen in liquid ethane. After $1 \mathrm{~h}$ storage in liquid nitrogen, samples were transferred into a home-built freeze dryer, based on conventional metal block cooled with liquid nitrogen, and samples were lyophilized for $48 \mathrm{~h}$.

\section{Experimental set-up beamline P06, PETRA III}

Measurements were performed at the P06 Hard X-ray Micro/ Nanoprobe at PETRA III, Hamburg, Germany. The primary beam is generated by a $2 \mathrm{~m}$ long spectroscopy undulator U32 having 60 periods with $31.4 \mathrm{~mm}$ period length and output power of $3.8 \mathrm{~kW}$. The beam was monochromatized by a $\mathrm{Si}(111)$ double crystal monochromator having an energy resolution of $1.4 \times$ $10^{-4} \Delta E / E$, set to a beam energy of $20.5 \mathrm{keV}$. A KB-system (JTEC Corporation, Osaka, Japan) was used to provide at the time of experiment a beam size of $0.5 \mu \mathrm{m}$ horizontally and $0.4 \mu \mathrm{m}$ vertically at a working distance of $200 \mathrm{~mm}$ measured from the second mirror, with an estimated flux density of approx. $10^{11}$ photons per s per $\mu \mathrm{m}^{2}$.

\section{Sample preparation for beamline ID22NI, ESRF}

In a $45 \mu \mathrm{l}$ droplet, $2.5 \times 10^{4}$ neutrophils in HEPES-buffered RPMI were seeded onto a $1.4 \mathrm{~mm}$ sapphire disk (Leica consumables no. 16706849). NET formation was induced by adding $100 \mathrm{nM}$ PMA or cells were left unstimulated. Stimulated cells were incubated for up to $4 \mathrm{~h}$ at $37{ }^{\circ} \mathrm{C}$ with $5 \% \mathrm{CO}_{2}$. Then, the medium was carefully removed, cells were washed twice very briefly with a droplet of ultraclean $\mathrm{H}_{2} \mathrm{O}$ (to avoid osmotic burst) and $50 \mu \mathrm{l}$ of $20 \% \mathrm{w} / \mathrm{v}$ BSA in PBS (Sigma) were added onto each sapphire disk as a cryoprotectant. Cells were in contact with the BSA-containing PBS only very briefly to minimize this inevitable step affecting the element integrity of the cells. The sapphire disc was then very quickly inserted in a membrane carrier (Leica consumables no. 16707898, $1.4 \mathrm{~mm}$ diameter, $100 \mu \mathrm{m}$ thickness) and frozen immediately in a high-pressure freezer (EM PACT; Leica Microsystems, Vienna, Austria). Freeze substitution was carried out using a Leica EM AFS2 (Leica Microsystems) in dry acetone with $0.1 \%$ glutaraldehyde over 4 days as follows: $-90{ }^{\circ} \mathrm{C}$ per hour increase for 15 hours, and $-30{ }^{\circ} \mathrm{C}$ for 24 hours. Samples were then washed 3 times in pure acetone and slowly warmed up to $4{ }^{\circ} \mathrm{C}$, infiltrated stepwise over 3 days at $4{ }^{\circ} \mathrm{C}$ in Spurr's resin (solution composed of NSA, ERL 4221, DER 736 and DMAE from emsdiasum.com, Hatfield) and embedded in capsules. The polymerization was performed at $70{ }^{\circ} \mathrm{C}$ for $16 \mathrm{~h}$. Ultrathin $(\sim 60 \mathrm{~nm})$ sections intended for EM were made using an ultramicrotome (Leica EM UC6) and post-stained in a Leica EM AC20 for $40 \mathrm{~min}$ in uranyl acetate at $20{ }^{\circ} \mathrm{C}$ and for $10 \mathrm{~min}$ in lead citrate at $20{ }^{\circ} \mathrm{C}$. Grids were viewed with a JEM 1010 transmission electron microscope (JEOL, Tokyo, Japan) operating at $80 \mathrm{kV}$ using Image Plate Technology from Ditabis (Pforzheim, Germany). Thin sections $(2 \mu \mathrm{m})$ were cut and deposited on square silicon nitride $\left(\mathrm{Si}_{3} \mathrm{~N}_{4}\right)$ ultra-thin membranes in square silicon nitride supporting frames from Silson Ltd, Northampton, UK $(3.0 \times 3.0 \mathrm{~mm}$ membrane size, $500 \mathrm{~nm}$ membrane thickness, $7.5 \times 7.5 \mathrm{~mm}$ frame size and $200 \mu \mathrm{m}$ frame thickness).

\section{Experimental set-up beamline ID22NI, ESRF}

The scanning nano-XRF experiments were performed at the ID22NI XRF nanoprobe at the European Synchrotron Radiation Facility (ESRF). This instrument was installed at a high- $\beta$ straight section equipped with two different undulators covering an energy range of 6-70 keV. The ID22NI nanoprobe (currently replaced by NINA) was dedicated to hard X-ray nanoanalysis allowing nano-XRF and absorption/phase contrast nanotomography. 
X-ray focusing was obtained by a crossed elliptical $\mathrm{Rh}$ coated graded-multilayer mirror-pair in the Kirkpatrick-Baez (KB) geometry. X-rays are collected and focused in both vertical and horizontal axis at a glancing angle $(<3.5 \mathrm{mrad})$. The first mirror, coated with a graded multilayer plays both the role of vertical focusing device and monochromator, resulting in a very high flux (exceeding $10^{11}$ photons per s) and a medium monochromaticity $\left(\Delta E / E \approx 10^{-2}\right)$. In our case the beam size was determined by knife-edge scans of a $\mathrm{Au}$ test pattern and determined to be $64 \mathrm{~nm}$ vertically and $54 \mathrm{~nm}$ horizontally at an excitation energy of $17 \mathrm{keV}$.

\section{Live cell imaging of $\mathrm{Zn}$ pool during NET formation}

Human neutrophils $\left(5 \times 10^{6}\right)$, stained with $20 \mu \mathrm{M}$ FluoZin-3 (Life Technologies), were seeded into a $35 \mathrm{~mm}$ glass bottom micro-well dish (MatTek, Ashland, MA, USA). Neutrophils were stimulated with $100 \mathrm{nM}$ PMA and kept at cell-culture conditions throughout the entire measurement $\left(5 \% \mathrm{CO}_{2}\right.$ and $\left.37{ }^{\circ} \mathrm{C}\right)$. Pictures, phase contrast and green fluorescence, were taken using a $60 \times$ objective every $2 \mathrm{~min}$ for a period of $2.5 \mathrm{~h}$ (beginning at $15 \mathrm{~min}$ post stimulation) using a Nikon eclipse Ti live-cell microscope operated by NIS-Elements AR 3.2. software.

\section{Quantification of SR-XRF measurements and image segmentation}

All quantitative results shown were obtained by measuring NIST standard reference materials (SRMs). For the ID22NI measurements (ESRF, Grenoble, France), a total amount of $17.4 \mathrm{mg}$ powder of NIST SRM $1577 \mathrm{c}$ (bovine liver) was pressed into a self-supporting pellet of $13 \mathrm{~mm}$ diameter resulting in an areal density of $13.11 \mathrm{mg} \mathrm{cm}^{-2}$. The pellet was measured for $1100 \mathrm{~s}$ using a raster scan to compensate for possible inhomogeneities. For the P06 beamline measurements (PETRA III, Hamburg, Germany), a NIST SRM 613 (trace elements in glass) and a MPI DING ATHO standard (both prepared as flat samples with a thickness of $100 \mu \mathrm{m}$ ) were measured for 1100 seconds using the same measuring strategy described previously. The obtained spectra were deconvoluted using analysis of X-ray spectra using Iterative Least squares $\mathrm{AXIL}^{53}$ to obtain the net line intensities, which were then normalised to the incoming photon flux, corrected for detector dead time and for self absorption effects. Spectral data was then batch processed using an inhouse developed software package called MICROXRF2. Manual image segmentation (or clustering) was performed on the obtained element maps of the unstimulated neutrophils, indicating nucleus, cytoplasm and cell. The individual point spectra belonging to a single segment were then summed and net line intensities of the segment were obtained using AXIL.

Quantification was based on a fundamental parameter approach which exploits the theoretical relation between the net-line intensities and the elemental concentrations (Sherman, 1955). The elemental yields of the elements of interest were calculated from the measured standard reference material taking into account: (1) variations in incoming beam intensity (related to varying synchrotron ring current and small variations in alignment of beamline optical components) by using ionisation chamber values, (2) the use of absorbers $(1500 \mu \mathrm{m} \mathrm{Al}$ in case of NIST SRM $1577 \mathrm{c}$ ) and (3) detector dead time (registered for every scanned point).

The elemental intensity maps were converted into areal concentration distributions (expressed in $\mu \mathrm{g} \mathrm{cm}^{-2}$ ) by dividing the pixel values in the normalised elemental maps (normalised to dead time and storage ring current) by the areal elemental yields. In order to determine the so-called "relative enrichment factors" for the relevant elements in the nucleus versus the cytoplasm, the sum spectra of the nucleus and the cytoplasm were first normalised to the Compton scattering peak and the ratios of the relevant elemental intensities were taken.

\section{Statistical analysis}

Unless stated otherwise, all statistical calculations have been performed using Microsoft Excel. Further statistical analysis was performed using Graphpad Prism Software 5. For the quantification of NETs supernatants, data was fitted using a non-linear Michaelis-Menten fit.

\section{Acknowledgements}

We would like to thank Quinten Remijsen for the help during the neutrophil stimulation experiment (Postdoctoral fellow FWO, VIB Department of Molecular Biomedical Research, Ghent University), Jaime Segura, Gema Martinez-Criado (ID22NI beamline staff, ESRF) and Ulrike Boesenberg (P06, Petra III, DESY) for their excellent technical support during the measurements, Maximillian Popp for support during ICP-MS analyses, Roland Nordfeldt for technical support, and also Lena Meyer and Patrick Engström for providing cultured cells. This work was supported by grants for C. F. Urban from the Swedish Research Council VR-M (2011-2393), the Laboratory for Molecular Medicine Sweden (MIMS), the Medial Faculty Umeå (316-886-10) and the Åke Wiberg Foundation (3772734). M. J. Niemiec acknowledges financial support from the J. C. Kempe Memorial Fund. B. De Samber receives a postdoctoral grant from the Fund for Scientific Research Flanders (FWO Vlaanderen, application number 12B3313N). Both E. Vergucht and J. Garrevoet are funded by $\mathrm{PhD}$ grants from the Flemish Institute for the Promotion of Scientific and Technological Research in Industry (IWT, Flanders, Belgium). Financial support by the Fund for Scientific Research Flanders (FWO Vlaanderen, Belgium) contract no. G.0395.11 \& Big Science program G.0C12.13 is acknowledged.

\section{References}

1 M. R. Bleackley and R. T. Macgillivray, BioMetals, 2011, 24, 785-809.

2 W. E. Winter, L. A. Bazydlo and N. S. Harris, Lab. Med., 2014, 45, 92-102.

3 M. Hershfinkel, E. Aizenman, G. Andrews and I. Sekler, Sci. Signaling, 2010, 3, mr2.

4 R. A. Festa and D. J. Thiele, Curr. Biol., 2011, 21, R877-R883.

5 J. Barber, Biochemistry, 2014, 79, 185-196. 
6 K. J. Waldron, J. C. Rutherford, D. Ford and N. J. Robinson, Nature, 2009, 460, 823-830.

7 M. I. Hood and E. P. Skaar, Nat. Rev. Microbiol., 2012, 10, 525-537.

8 R. Sutak, E. Lesuisse, J. Tachezy and D. R. Richardson, Trends Microbiol., 2008, 16, 261-268.

9 T. E. Kehl-Fie and E. P. Skaar, Curr. Opin. Chem. Biol., 2010, 14, 218-224.

10 Y. Fu, F. M. Chang and D. P. Giedroc, Acc. Chem. Res., 2014, 47, 3605-3613.

11 D. R. Soll, G. W. Bedell and M. Brummel, Infect. Immun., 1981, 32, 1139-1147.

12 D. J. Eide, Biochim. Biophys. Acta, 2006, 1763, 711-722.

13 L. Decaria, I. Bertini and R. J. Williams, Metallomics, 2010, 2, 706-709.

14 C. Y. Wu, J. Steffen and D. J. Eide, PLoS One, 2009, 4, e7061.

15 G. W. Bedell and D. R. Soll, Infect. Immun., 1979, 26, 348-354.

16 E. Kolaczkowska and P. Kubes, Nat. Rev. Immunol., 2013, 13, 159-175.

17 N. Borregaard, Immunity, 2010, 33, 657-670.

18 N. Borregaard, O. E. Sorensen and K. Theilgaard-Monch, Trends Immunol., 2007, 28, 340-345.

19 O. Nusse, Sci. World J., 2011, 11, 2364-2381.

20 V. Brinkmann, U. Reichard, C. Goosmann, B. Fauler, Y. Uhlemann, D. S. Weiss, Y. Weinrauch and A. Zychlinsky, Science, 2004, 303, 1532-1535.

21 T. A. Fuchs, U. Abed, C. Goosmann, R. Hurwitz, I. Schulze, V. Wahn, Y. Weinrauch, V. Brinkmann and A. Zychlinsky, J. Cell Biol., 2007, 176, 231-241.

22 C. F. Urban, D. Ermert, M. Schmid, U. Abu-Abed, C. Goosmann, W. Nacken, V. Brinkmann, P. R. Jungblut and A. Zychlinsky, PLoS Pathog., 2009, 5, e1000639.

23 M. Bianchi, M. J. Niemiec, U. Siler, C. F. Urban and J. Reichenbach, J. Allergy Clin. Immunol., 2011, 127, 1243-1252.

24 S. M. Damo, T. E. Kehl-Fie, N. Sugitani, M. E. Holt, S. Rathi, W. J. Murphy, Y. Zhang, C. Betz, L. Hench, G. Fritz, E. P. Skaar and W. J. Chazin, Proc. Natl. Acad. Sci. U. S. A., 2013, 110, 3841-3846.

25 B. D. Corbin, E. H. Seeley, A. Raab, J. Feldmann, M. R. Miller, V. J. Torres, K. L. Anderson, B. M. Dattilo, P. M. Dunman, R. Gerads, R. M. Caprioli, W. Nacken, W. J. Chazin and E. P. Skaar, Science, 2008, 319, 962-965.

26 L. Mueller, H. Traub, N. Jakubowski, D. Drescher, V. I. Baranov and J. Kneipp, Anal. Bioanal. Chem., 2014, 406, 6963-6977.

27 A. Martin-Camean, A. Jos, A. Calleja, F. Gil, A. Iglesias, E. Solano and A. M. Camean, Talanta, 2014, 118, 238-244.

28 E. Bjorn, Y. Nygren, T. T. Nguyen, C. Ericson, M. Nojd and P. Naredi, Anal. Biochem., 2007, 363, 135-142.

29 R. Evens, K. A. De Schamphelaere, B. De Samber, G. Silversmit, T. Schoonjans, B. Vekemans, L. Balcaen, F. Vanhaecke, I. Szaloki, K. Rickers, G. Falkenberg, L. Vincze and C. R. Janssen, Environ. Sci. Technol., 2012, 46, 1178-1184.
30 R. Cesareo and G. Viezzoli, Phys. Med. Biol., 1983, 28, 1209-1218.

31 S. Bohic, K. Murphy, W. Paulus, P. Cloetens, M. Salome, J. Susini and K. Double, Anal. Chem., 2008, 80, 9557-9566.

32 R. Ortega, C. Bresson, A. Fraysse, C. Sandre, G. Deves, C. Gombert, M. Tabarant, P. Bleuet, H. Seznec, A. Simionovici, P. Moretto and C. Moulin, Toxicol. Lett., 2009, 188, 26-32.

33 R. Ortega, P. Cloetens, G. Deves, A. Carmona and S. Bohic, PLoS One, 2007, 2, e925.

34 T. Leonardo, E. Farhi, A. M. Boisson, J. Vial, P. Cloetens, S. Bohic and C. Rivasseau, Metallomics, 2014, 6, 316-329.

35 D. Deruytter, J. Garrevoet, M. B. Vandegehuchte, E. Vergucht, B. De Samber, B. Vekemans, K. Appel, G. Falkenberg, K. Delbeke, R. Blust, K. A. De Schamphelaere, L. Vincze and C. R. Janssen, Environ. Sci. Technol., 2014, 48, 698-705.

36 J. Lam, M. Herant, M. Dembo and V. Heinrich, Biophys. J., 2009, 96, 248-254.

37 Y. Shi, D. D. Ryu and R. Ballica, Biotechnol. Bioeng., 1993, 41, 745-754.

38 A. Hosseinzadeh, P. K. Messer and C. F. Urban, Front. Immunol., 2012, 3, 391.

39 H. R. Lopez-Mirabal and J. R. Winther, Biochim. Biophys. Acta, 2008, 1783, 629-640.

40 W. G. Rice, J. M. Kinkade, Jr. and R. T. Parmley, Blood, 1986, 68, 541-555.

41 H. U. Keller, J. Cell. Physiol., 1990, 145, 465-471.

42 T. Vogl, N. Leukert, K. Barczyk, K. Strupat and J. Roth, Biochim. Biophys. Acta, 2006, 1763, 1298-1306.

43 L. Tapia, M. Suazo, C. Hodar, V. Cambiazo and M. Gonzalez, BioMetals, 2003, 16, 169-174.

44 G. L. Smith, R. A. Jenkins and J. F. Gough, J. Histochem. Cytochem., 1969, 17, 749-750.

45 S. J. Klebanoff, J. Leukocyte Biol., 2005, 77, 598-625.

46 N. A. Maianski, J. Geissler, S. M. Srinivasula, E. S. Alnemri, D. Roos and T. W. Kuijpers, Cell Death Differ., 2004, 11, 143-153.

47 H. Parker, A. M. Albrett, A. J. Kettle and C. C. Winterbourn, J. Leukocyte Biol., 2012, 91, 369-376.

48 J. Johnston, J. Bollekens, R. H. Allen and N. Berliner, J. Biol. Chem., 1989, 264, 15754-15757.

49 F. Gil, A. F. Hernandez, C. Marquez, P. Femia, P. Olmedo, O. Lopez-Guarnido and A. Pla, Sci. Total Environ., 2011, 409, 1172-1180.

50 N. B. Ivanenko, A. A. Ivanenko, N. D. Solovyev, A. E. Zeimal, D. V. Navolotskii and E. J. Drobyshev, Talanta, 2013, 116, 764-769.

51 M. S. Winters, Q. Chan, J. A. Caruso and G. S. Deepe, Jr., J. Infect. Dis., 2010, 202, 1136-1145.

52 D. Wagner, J. Maser, B. Lai, Z. Cai, C. E. Barry, 3rd, K. Honer $\mathrm{Zu}$ Bentrup, D. G. Russell and L. E. Bermudez, J. Immunol., 2005, 174, 1491-1500.

53 B. Vekemans, K. Janssens, L. Vincze, F. Adams and P. Vanespen, X-Ray Spectrom., 1994, 23, 278-285. 